\title{
Strategies to improve the management of upper respiratory tract infections and reduce inappropriate antibiotic use particularly among lower and middle-income countries; findings and implications
}

Brian Godman 1,2,3,4*, Mainul Haque ${ }^{5}$, Judy McKimm ${ }^{6}$, Muhamad Abu Bakar ${ }^{7}$, Jacqueline Sneddon ${ }^{8}$, Janney Wale ${ }^{9}$, Stephen Campbell ${ }^{10,11}$, Antony P Martin ${ }^{3}$, Iris Hoxha ${ }^{12}$, Vafa Abilova ${ }^{13}$, Bene D Anand Paramadhas $^{14}$, Pinkie Mpinda-Joseph ${ }^{15}$, Matshediso Matome ${ }^{16}$, Livia Lovato Pires de Lemos ${ }^{17}, 18$, Israel Sefah ${ }^{19}$, Amanj Kurdi ${ }^{1,20}$, Sylvia Opanga ${ }^{21}$, Arianit Jakupi ${ }^{22}$, Zikria Saleem ${ }^{4,23}$, Mohamed Azmi Hassali ${ }^{4}$, Dan Kibuule ${ }^{24}$, Joseph Fadare ${ }^{25}$, Tomasz Bochenek ${ }^{26}$, Celia Rothe ${ }^{26}$, Jurij Furst ${ }^{27}$, Vanda Markovic-Pekovic ${ }^{28}$, Ljubica Bojanić30,31, Natalie Schellack ${ }^{2}$, Johanna C Meyer ${ }^{2}$, Zinhle Matsebula ${ }^{32}$, Thuy Nguyen Thi Phuong ${ }^{33}$, Binh Nguyen Thanh ${ }^{33}$, Saira Jan ${ }^{34,35}$, Aubrey Kalungia ${ }^{36}$, Sekesai Mtapuri-Zinyowera $^{37}$, Massimo Sartelli ${ }^{38}$, Ruaraidh Hill ${ }^{39}$

${ }^{1}$ Strathclyde Institute of Pharmacy and Biomedical Sciences, University of Strathclyde, Glasgow G4 ORE, United Kingdom. Email: amanj.baker@strath.ac.uk; brian.godman@strath.ac.uk

${ }^{2}$ School of Pharmacy, Faculty of Health Sciences, Sefako Makgatho Health Sciences University,

Pretoria, South Africa. Email: natalie.schellack@smu.ac.za; hannelie.meyer@smu.ac.za

${ }^{3}$ Health Economics Centre, University of Liverpool, Liverpool, UK. Email:

Brian.Godman@liverpool.ac.uk; a.p.martin@liverpool.ac.uk

${ }^{4}$ School of Pharmaceutical Sciences, Universiti Sains Malaysia, Penang, Malaysia. Email:

azmihassali@gmail.com

${ }^{5}$ Unit of Pharmacology, Faculty of Medicine and Defence Health, Universiti Pertahanan Nasional

Malaysia (National Defence University of Malaysia), Kem Sungai Besi, 57000 Kuala Lumpur,

Malaysia, Email: runurono@gmail.com

${ }^{6}$ Swansea University School of Medicine, Grove Building, Swansea University, Singleton Park, Swansea, Wales SA2 8PP, UK. Email: j.mckimm@swansea.ac.uk

${ }^{7}$ Unit of Otolaryngology, Faculty of Medicine and Defence Health, Universiti Pertahanan Nasional

Malaysia (National Defence University of Malaysia), Kem Sungai Besi, 57000 Kuala Lumpur,

Malaysia. Email: muhamadbakar@upnm.edu.my

${ }^{8}$ Healthcare Improvement Scotland, Delta House, 50 West Nile Street, Glasgow G1 2NP, UK. Email: jacqueline.sneddon@nhs.net

9Independent consumer advocate, 11a Lydia Street, Brunswick, Victoria 3056 Australia. Email: socrates111@bigpond.com

${ }^{10}$ Centre for Primary Care, Division of Population Health, Health Services Research and Primary

Care, University of Manchester, Manchester, M13 9PL, UK. Email:

stephen.campbell@manchester.ac.uk

${ }^{11} \mathrm{NIHR}$ Greater Manchester Patient Safety Translational Research Centre, School of Health

Sciences, University of Manchester, Manchester, UK

${ }^{12}$ Department of Pharmacy, Faculty of Medicine, University of Medicine Tirana, Albania. Email:

iris.hoxha@umed.edu.al

${ }^{13}$ Analytical Expertise Center, Ministry of Health, Baku, Azerbaijan Republic. Email: abilovafa@mail.ru

${ }^{14}$ Department of Pharmacy, Nyangabgwe Hospital, Francistown, Botswana. Email:

anandbene@yahoo.com

${ }^{15}$ Infection Prevention and Control Coordinator, Nyangabgwe Hospital, Francistown, Botswana. Email:

pnkmpinda@gmail.com

${ }^{16}$ Managed Care, AFA, Showgrounds Office Park, Gaborone, Botswana. Email:

matshedisom@afa.co.bw

${ }^{17}$ SUS Collaborating Centre for Technology Assessment \& Excellence in Health, sala 1042,

Faculdade de Farmácia, Universidade Federal de Minas Gerais, Av. Presidente Antônio Carlos, 6627, Campus Pampulha, Belo Horizonte, Minas Gerais, CEP 31270-901, Brazil. Email:

lilolemos@gmail.com

${ }^{18}$ Programa de Pós-Graduação em Saúde Pública, sala 533 , Faculdade de Medicina, Universidade

Federal de Minas Gerais, Av. Porf. Alfredo Balena, 190, Campus Saúde, Belo Horizonte, Minas

Gerais, CEP 30130-100, Brazil

${ }^{19}$ Department of Pharmacy, Keta Municipal Hospital, Ghana Health Service, Ghana. Email:

sefrael@yahoo.com

${ }^{20}$ Department of Pharmacology, College of Pharmacy, Hawler Medical University, Erbil, Iraq

${ }^{21}$ Department of Pharmacology and Pharmacognosy, School of Pharmacy, University of Nairobi, P.O

Box 19676-00202, Nairobi, Kenya. Email: sopanga@uonbi.ac.ke 
22UBT - Higher Education Institute, Prishtina, Kosovo. Email: arianit.jakupi@rks-gov.net; arianiti@gmail.com

${ }^{23}$ Hamdard Institute of Pharmaceutical Sciences, Hamdard University, Islamabad, Pakistan. Email: xikria@gmail.com

${ }^{24}$ Department of Pharmacy Practice and Policy, Faculty of Health Sciences, University of Namibia, Windhoek, Namibia. E-mail: dkibuule@unam.na

${ }^{25}$ Department of Pharmacology and Therapeutics, Ekiti State University, Ado-Ekiti, Nigeria. Email: joseph.fadare@eksu.edu.ng

${ }^{26}$ Department of Drug Management, Faculty of Health Sciences, Jagiellonian University Medical College, Krakow, Poland. Email: mxbochen@cyf-kr.edu.pl; celia.rothe@outlook.de

${ }^{27}$ Health Insurance Institute, Miklosiceva 24, SI-1507 Ljubljana, Slovenia. Email: Jurij.Furst@zzzs.si

${ }^{28}$ Department of Social Pharmacy, Faculty of Medicine, University of Banja Luka, Republic of Srpska,

Bosnia and Herzegovina, Email: vanda.markovic-pekovic@med.unibl.org

${ }^{29}$ Public Health Institute, Banja Luka, Republic of Srpska, Bosnia and Herzegovina, Email:

ljubica.bojanic@phi.rs.ba

${ }^{30}$ Department of Pharmacy, Faculty of Medicine, University of Banja Luka, Banja Luka, Republic of

Srpska, Bosnia and Herzegovina

${ }^{31}$ Raleigh Fitkin Memorial Hospital, Manzini, Swaziland. Email: zmkholo@gmail.com

${ }^{32}$ Pharmaceutical Administration \& PharmacoEconomics, Hanoi University of Pharmacy, Vietnam.

Email: thuy_ntp@hup.edu.vn; binhnt@hup.edu.vn

${ }^{33}$ Clinical Pharmacy, Rutgers State University of New Jersey, Piscataway, New Jersey, USA

${ }^{34}$ Pharmacy Strategy and Clinical Integration, Horizon Blue Cross Blue Shield of New Jersey. Email:

Saira_Jan@horizon-bcbsnj.com

35Department of Pharmacy, University of Zambia, Lusaka, Zambia. Email: ckalungia@unza.zm

${ }^{36}$ National Microbiology Reference Laboratory, Harare, Zimbabwe. Email:

zinyowerasekesai@gmail.com

${ }^{37}$ Department of Surgery, University of Macerata, Macerata Hospital, Via Giovanni Mario Crescimbeni, 28, 62100 Macerata MC, Italy. Email: massimosartelli@infectionsinsurgery.org

${ }^{38}$ Liverpool Reviews and Implementation Group, Whelan Building, Liverpool University, Liverpool, UK

L693GB. Email: ruaraidh.hill@liverpool.ac.uk

\section{Address of Correspondence}

*Author for correspondence: Strathclyde Institute of Pharmacy and Biomedical Sciences, University of Strathclyde, Glasgow G4 ORE, United Kingdom. Email: Brian.godman@strath.ac.uk. Telephone: 0141548 3825. Fax: 01415522562 and Division of Clinical Pharmacology, Karolinska Institute, Karolinska University Hospital Huddinge, SE-141 86, Stockholm, Sweden. Email:

Brian.Godman@ki.se. Telephone + 468 58581068. Fax + 46859581070

(Accepted for publication Current Medical Opinion and Research)

\section{ABSTRACT}

Introduction: Antibiotics are indispensable to maintaining human health; however, their overuse has resulted in resistant organisms increasing morbidity, mortality and costs. Increasing antimicrobial resistance (AMR) is a major public health threat resulting in multiple campaigns across countries to improve appropriate antimicrobial use. This includes addressing the over use of antimicrobials for self-limiting infections such as upper respiratory tract infections (URTIs), particularly in lower- and middle-income countries (LMICs) where this is greatest inappropriate use and where antibiotic utilisation has increased the most in recent years. Consequently, there is a need to document current practices and successful initiatives in LMICs to improve future antimicrobial use.

Methodology: Documentation of current epidemiology and management of URTIs particularly in LMICs as well as campaigns to improve future antimicrobial use. Results: There is still considerable concern regarding the prescribing and dispensing of antibiotics for URTIs among LMICs. This includes considerable self-purchasing, up to $100 \%$ of pharmacies in some LMICs. However, multiple activities are now ongoing to improve future use. These incorporate educational initiatives among all key stakeholder groups as well as legislation and other activities to reduce self-purchasing as part of National Action Plans (NAPs). Further activities are still needed though. These include increased 
physician and pharmacist education starting in medical and pharmacy schools, greater monitoring of prescribing and dispensing practices including the development of pertinent quality indicators as well as targeted patient information and health education campaigns. It is recognised that such activities are more challenging in LMICs given more limited resources and a lack of healthcare professionals. Conclusion: Initiatives will grow across LMICs to reduce inappropriate prescribing and dispensing of antimicrobials for URTIs as part of NAPs and other activities, and these will be monitored

\section{INTRODUCTION}

The development of antimicrobial resistance (AMR) is a major issue world-wide, associated with increasing morbidity, mortality and health care costs (1-16). Globally, the irrational, indiscriminate, and excessive use of antibiotics, including for self-limiting infections, is a key driver of increasing AMR rates and a considerable public health concern $(4,9,17-30)$. Such concerns are exacerbated by the spread of AMR from one geographic locality to others resulting in resistance to reserve antibiotics including colistin together with a number of organisms including Klebsiella pneumoniae, Escherichia coli, Salmonella typhi and Neisseria gonorrhoeae growing (18, 31-36). As a result, bacteria causing severe health problems have become resistant to multiple antibiotics during the past $20-30$ years $(18,37,38)$. This overuse urgently needs addressing alongside the development and implementation of guidelines to restrict the use of key antibiotics as well as reduce their inappropriate use (39-41).

High AMR rates are a particular issue in LMICs, exacerbated by poor hygiene, malnutrition and overcrowded living conditions, lack of adequate infrastructures and pressure by patients and carers on physicians to prescribe antibiotics and on pharmacists to dispense them without a prescription $(13,14,19,21,42-55)$. Unfortunately, antibiotics can achieve good health outcomes even in patients with viral infections, which runs counter to changing public perceptions of their efficacy (56-59). Concerns with rising rates of AMR, coupled with the continued irrational use of antibiotics to treat self-limiting infections such as upper respiratory tract infections (URTIs), have resulted in multiple initiatives internationally, regionally, and nationally aimed at reversing current trends $(6,8,21,36$, 40, 60-74).

URTIs, which include infections of the nose, nasal cavity, pharynx, and larynx with the subglottic area of the trachea, are the most common infections seen in ambulatory care $(17,28,75-83)$. The majority of these infections are viral in origin, involving any part [more or less] of the upper respiratory tract $(80,83-88)$, and will typically resolve without the use of antibiotics $(21,83,85,89$ 95). Consequently, the inappropriate use of antibiotics in respiratory tract infections (RTIs) will appreciably enhance AMR rates with antimicrobial use in RTIs seen as the greatest misuse of antimicrobials worldwide $(88,96)$.

Sub-optimal management of URTIs in LMICs including the overuse of antibiotics is promoted by misconceptions, social-cultural issues, diagnostic uncertainty, and clinical competency as well as commercial, patient and time pressures (21, 29, 50, 52, 57, 92, 96-109). Inappropriate management is also a concern in countries with high rates of infectious diseases such as HIV, malaria and tuberculosis (TB), which is the case in sub-Saharan Africa, as this may complicate treatment (110112). Certain antibiotics temporarily suppress symptoms of TB, leading to delays in diagnosis and patients potentially receiving several antibiotics due to the wrong clinical diagnosis (113). Ideally, patients with TB should be referred by pharmacists to specialists if patients first visit them. However, such activities can be very variable and may depend on whether patients have suspected or confirmed TB $(113,114)$. Development of AMR in patients with RTIs and other underlying infectious diseases can increase morbidity and mortality; consequently, antibiotic use in such patients needs to be carefully managed (115). 
In view of growing AMR rates and the implications of this, there is an urgent need to review key issues relating to the use of antibiotics for patients with URTIs as well as potential strategies to reduce irrational use to guide future activities. This is because a considerable proportion of antibiotics prescribed and dispensed worldwide are in ambulatory care, and, as mentioned, predominantly for URTIs $(21,82,85,88,90,116-118)$. There is also a need to focus on LMICs, including sub-Saharan Africa, because infectious disease rates are higher in LMICs than in developed countries, there is extensive self-purchasing of antibiotics in LMICs because of their relatively easy availability, and issues surrounding their inappropriate use have been less well researched and understood in LMICs compared with higher income countries $(43,45,49,100,104,119-124)$. In addition, a considerably higher percentage of patients with URTIs are inappropriately treated in LMICs compared with high income countries (88). In addition, much of the increase in antibiotic consumption in recent years has been in LMICs including Brazil, China, India and South Africa (11, 125-127). Overall between 2000 and 2015, worldwide consumption of antibiotics increased by 65\%, driven principally by increased rates in $\operatorname{LMICs}(11,12)$.

Self-purchasing of antibiotics, sometimes referred to as 'non-prescription sales', can be a particular concern in terms of the accuracy of diagnosis and the over-use of antibiotics, enhanced by issues of accessibility, affordability (i.e. whether patients can afford to see both a physician and purchase their medicines) and economic benefits. In addition in some situations, pharmacists are the only healthcare professional available to patients $(47,128-141)$. Self-purchasing of antimicrobials is particularly problematic in LMICs compared with high income countries $(49,52,120,121,123,142$, 143).

Consequently, the principal objective of this paper is to document and debate key issues surrounding antibiotic use, including misuse, in ambulatory care patients with URTIs in LMICs to provide future guidance. The includes identifying and building on suggested activities from the published literature supplemented by knowledge and experience from key senior personnel working in this area across LMICs. We did not consider the quality of available antibiotics in this paper, which have resulted in concerns with generic antibiotics and/ or counterfeit medicines, as these issues have been extensively explored elsewhere (144-148). We also did not consider antibiotic availability, which can also be a concern in LMICs (149). The key issue discussed in this paper is potential ways to reduce rising AMR rates given the high global priority via the appropriate management of URTIs in $\operatorname{LMICs}(29,88,125,150)$.

We are aware that an appreciable number of publications and ongoing research already exist discussing potential ways to improve antibiotic utilization especially in LMICs, which includes improved surveillance $(29,45,61,66,85,100,119,120,151,152)$. A number of systematic reviews regarding the management of URTIs and ways to improve both the prescribing and dispensing of antibiotics for patients with URTIs have also been published $(21,43,45,57,61,74,85,108,153$, 154). These include systematic reviews determining possible reasons behind dispensing antibiotics without a prescription $(141,155)$, patient-related determinants regarding antibiotic use $(156)$, and reviews assessing the influence of targeted communications among patients to reduce excessive antibiotic use (157). In addition, there are initiatives such as GRIP (Global Respiratory Infection Partnership Declaration) to help reduce unnecessary antibiotic utilisation through recommending non-antibiotic treatments for patients with URTIs $(158,159)$. However, we believe to date there have not been any publications that have comprehensively focused on all aspects of prescribing and dispensing of antibiotics for URTIs in LMICs, which can be very different to high income countries with different practices and beliefs. In addition, few reviews have contextualised the findings from multiple authors from a wide range of LMICs to provide future guidance building on WHO and other international initiatives. Consequently, we believe our findings and the implications should be of interest to all key stakeholders in LMICs seeking ways to improve antibiotic utilization among their patients with URTIs. 


\section{METHODOLOGY}

A systematic review was not performed as there have already been an appreciable number of recent publications, including systematic reviews, discussing ongoing research in this area, which includes current self-purchasing rates as well public awareness campaigns $(29,43,45,49,57,61,66,74,85$, $100,108,119,120,123,141,151-157,160)$.

Consequently, our findings and suggested activities for key stakeholder groups is based on relevant publications known to the authors, coupled with their considerable knowledge of ongoing activities in their own countries (and more broadly) to improve the prescribing and dispensing of antibiotics for patients with URTIs. This approach has been used successfully to stimulate debate in other priority healthcare areas to provide future guidance (161-171).

The 2018 World Bank classification was used to break countries down into LMICs or upper income countries where applicable (172) (Supplement - Table A). Upper income countries are only commented on where pertinent. This is because typically there are different practices, cultural beliefs as well as a greater availability of healthcare professionals in higher income countries. In addition in LMICs, the costs of medicines can account for up to $70 \%$ of total healthcare expenditure, much of which is out of pocket (173-175). This is again very different to high income countries where typically expenditure on pharmaceuticals is $15 \%$ or less of total healthcare expenditure and there is often universal healthcare $(176,177)$. There can also be long waiting times to see physicians in primary healthcare centres (PHCS) in LMICs, as well as long distances to travel to PHCs, putting time pressures on physicians as well as patients to seek alternative approaches including community pharmacists and private physicians $(49,69,98,178-182)$.

We have not documented prescription rates for antibiotics to treat URTIs in LMICs in view of the difficulties with obtaining reliable data as well as high rates of self-purchasing of antimicrobials. However, this is starting to be addressed in LMICs (183). We have though documented the impact of different interventions and initiatives where published to provide future direction. We have also not divided LMICs into different continents and regions as they share many of the same characteristics.

\section{Results}

The aetiology of URTIs and their symptoms will first be discussed followed by known prevalence rates for URTIs and factors influencing their prescribing to provide a background before discussing the management of URTIs in LMICs including non-prescription sales. This will be followed by documenting and debating potential strategies to reduce the irrational use of antibiotics to treat URTIs in LMICs to provide future direction.

\subsection{Aetiology of URTIs and Symptoms}

URTIs can develop from 24-72 hours of neonatal life right up to an advanced age, with a number of viruses implicated (184-189). The principal invading viruses include the human rhinovirus/enterovirus, respiratory syncytial virus, the parainfluenza virus, adenovirus, coronavirus and the H1N1 flu virus $(185-187,190)$. However, there can be bacterial involvement, including Group A beta-haemolytic Streptococcus, Streptococcus pneumoniae, Haemophilus influenzae, Moraxella catarrhalis and Mycoplasma pneumoniae (138, 185, 188, 191-193).

URTIs are often reported as a minor health problem (184). For instance, the common cold is viral in origin and generally mild and self-limiting, with patients typically improving within 7 to 10 days of onset $(99,189,194,195)$. Children of six years or below are the most vulnerable to develop a common cold, with young children typically having six to eight cold episodes per year, whereas 
adults typically have only two to three common colds a year (189). Smokers generally suffer the symptoms of URTIs for longer than non-smokers (194).

Typically, a medical consultation is not needed for URTIs if symptoms resolve within ten days since, as mentioned, URTIs are frequently viral in origin, generally self-limiting and hardly ever lifethreatening $(88,196,197)$. However, some children can develop pneumonia, which requires hospitalisation and specialised treatment (198). Despite URTIs generally being a minor illness, they do result in an appreciable number of medical consultations globally $(87,199-203)$. The number of healthcare consultations combined with parental and patient pressure enhances antibiotic use for URTIs including LMICs thereby increasing AMR rates (88, 153, 200, 204-209). Patients who are concerned about their or their child's respiratory illness are likely to seek treatment, and likely to want an antibiotic, especially if they perceive the illness as severe $(21,209,210)$. As mentioned, extra care is needed for patients with underlying infectious diseases such as HIV, malaria and TB, especially in tropical countries. These infections may compound the diagnosis and treatment of URTIs particularly where no laboratory facilities for definitive diagnosis are available. For example, a study undertaken in Kenya in a malaria endemic zone at the peak malaria infection period demonstrated a high rate of viral respiratory tract infections (52\%) among children suspected of having malaria using clinical symptoms only (211). These children are more likely to be treated for malaria than URTIs as it was demonstrated they had gained immunity to plasmodium parasites by being in a malaria endemic zone (211).

\subsection{Epidemiology of URTIs}

It is difficult to fully estimate the prevalence of URTIs especially in LMICs where extensive selfpurchasing of antibiotics occurs $(42,43,49,123,212)$. Overall, the incidence and prevalence of URTIs varies considerably across and within countries and across age groups, although children from newborn to four years are at the highest risk of developing a URTI $(69,188,213-218)$. Females may be at more risk of developing URTIs than males; however, this is not always the case and may depend on the patient's age $(189,213,215,219)$.

Supplement Table B in the Appendix contains further details of epidemiology rates for URTIs in both high income countries as well as LMICs.

\subsection{Factors influencing antimicrobial utilization in URTIs}

Group A beta-haemolytic streptococcus (GABHS) is the most common bacterial cause of acute pharyngitis; however, culture and sensitivity testing (CST) can take up to 48 hours for the results and an appreciable number of URTIs are viral in origin anyway (220-222). However, rapid antigen detection tests (RADTs) for GABHS take only 5 to 10 minutes to perform and can reduce unnecessary antibiotic prescribing (222). Consequently, their use is likely to grow in the future (152).

Alternatively, clinical scoring systems such as FeverPAIN or Centor criteria help to reduce inappropriate prescribing of antibiotics for acute sore throats, including acute pharyngitis $(223,224)$.

\subsection{Physician management of URTIs in LMICs}

Ideally, physicians should consider multiple issues when treating patients with URTIs including the potential use, delayed use or misuse of antibiotics $(151,192,225-227)$. This is especially important as there is no perceived clinical benefit from the use of antibiotics in the treatment of URTIs in many patients, including those with a common cold or persistent acute purulent rhinitis, with evidence of significant adverse events in adults from antibiotics $(21,27,85,228)$. However, as mentioned, there is a need for care in patients with other underling infectious diseases such as HIV, malaria, and TB. 
Despite this lack of benefit, considerable prescribing and dispensing of antibiotics still occurs for patients with URTIs especially in LMICs $(21,87,88,92,120,209,227,229,230)$, although rates vary appreciably across countries. For example, Holloway et al found in their recent review that the rates of treating URTIs inappropriately in children in LMICs were high, with the use of antibiotics ranging from $42 \%$ to $72 \%$ of patients (97), and Ahiabu et al found that $86.4 \%$ of patients with URTIs attending primary healthcare facilities in Ghana were prescribed an antibiotic (231). Table 1 documents prescribing practices for patients with URTIs across a range of LMICs whilst Table $\mathrm{C}$ in the Supplement contains details of prevalence rates from a number of higher income countries for comparative purposes.

Table 1: Prescribing Practices for Patients with Respiratory Tract Infections among LMICs

\begin{tabular}{|c|c|}
\hline Country & Antibiotic utilization \\
\hline $\begin{array}{ll}\text { LMICs } & (8 \\
\text { countries })\end{array}$ & $\begin{array}{l}33 \% \text { of children under five in eight LMICs were reported to have either a cough } \\
\text { or fever in the past two weeks, with } 86 \% \text { of young children attending health } \\
\text { facilities being prescribed an antibiotic (amoxicillin - 38.0\%, cotrimoxazole } \\
27.8 \% \text { ) for their respiratory infection (183) }\end{array}$ \\
\hline Botswana & $\begin{array}{l}72.9 \% \text { of ambulatory care patients in the private sector had at least one } \\
\text { antibiotic dispensed for a URTI }(180,232) \text {. }\end{array}$ \\
\hline China & $\begin{array}{l}\text { Among physicians working in rural China, the antibiotic prescription rate for } \\
\text { children with URTIs was } 84 \% \text { before multiple interventions to reduce } \\
\text { inappropriate prescribing ( } 88 \text { ) }\end{array}$ \\
\hline Ghana & $\begin{array}{l}\text { An audit of antibiotic prescriptions among four public and private PHCs showed } \\
\text { that over } 86 \% \text { of patients diagnosed with an URTI were prescribed an } \\
\text { antibiotic, mostly a broad-spectrum antibiotic (231). }\end{array}$ \\
\hline India & $\begin{array}{l}\text { - } 45 \% \text { of patients in the public sector and } 57 \% \text { of patients in the private } \\
\text { sector with acute respiratory tract infections were prescribed at least one } \\
\text { antibiotic (233) } \\
\text { - In another study, } 46 \% \text { of patients had taken an antibiotic for a URTI, either } \\
\text { prescribed or self-purchased ( } 234 \text { ) }\end{array}$ \\
\hline Namibia & $\begin{array}{l}\text { - The rate of antibiotic prescribing among patients with URTIs at a regional } \\
\text { referral hospital was } 78 \%(235) \\
\text { - This was no doubt enhanced by current antibiotic policies in Namibia } \\
\text { promoting the over-prescribing of cotrimoxazole, amoxicillin and } \\
\text { azithromycin in the public sector (236) }\end{array}$ \\
\hline Nigeria & $\begin{array}{l}\text { - } 56.4 \% \text { of physicians surveyed treated children with a sore throat } \\
\text { empirically with an antibiotic. This was despite a similar percentage of } \\
\text { physicians believing viruses were the commonest cause of pharyngitis } \\
\text { (237) } \\
\text { - In a study conducted among } 423 \text { nursing mothers, the authors reported } \\
\text { the use of unprescribed antibiotics for the treatment of URTIs in } 75.9 \% \text { of } \\
\text { cases (238) }\end{array}$ \\
\hline Malaysia & $\begin{array}{l}\text { - Study one (2015) - In the public healthcare system, } 31.8 \% \text { of prescriptions } \\
\text { for a URTI included an antibiotic, an improvement though on previous } \\
\text { studies (over 60\%) (69) } \\
\text { - Study two (2015) - Among GPs in the private sector, } 49.6 \% \text { felt antibiotics } \\
\text { were helpful in treating URTIs, with most GPs believing patients expected } \\
\text { an antibiotic for a URTI enhancing their use (98) } \\
\text { Study } 3 \text { (2016) (239) } \\
\text { - Among both private and public primary care clinics, there is greater } \\
\text { prescribing of antibiotics in private clinics }\end{array}$ \\
\hline
\end{tabular}




\begin{tabular}{|l|l|}
\hline & $\begin{array}{l}\text { URTIs were the most frequent diagnosis in patients receiving an antibiotic, } \\
\text { accounting for } 49.2 \% \text { of all prescriptions } \\
\text { Of those diagnosed with an URTI, } 46.2 \% \text { received antibiotic treatment } \\
\text { greater in private }(57.7 \%) \text { versus public (16.8 \%) clinics with penicillins, } \\
\text { cephalosporins and macrolides the most commonly prescribed antibiotics }\end{array}$ \\
\hline Zimbabwe & $\begin{array}{l}37 \% \text { of nurses, who are often involved in managing patients in public health } \\
\text { care centres in sub-Sahara Africa, believed antibiotics accelerated recovery in } \\
\text { patients with influenza, enhancing their overuse (240) }\end{array}$ \\
\hline
\end{tabular}

NB: $\mathrm{RTI}=$ respiratory tract infection; URTI = upper respiratory tract infection

Among LMICs generally, considerable self-purchasing of antibiotics still occurs. This averages $38.8 \%$ to $58 \%$ across countries, with higher rates seen in some continents including Africa and South America $(43,49,120,142,143)$. However, rates do vary across and within countries, as well as populations within countries. Supplement Table $C$ gives details of a range of prevalence rates for non-prescription sales of antibiotics for common diseases, including respiratory infections incorporating URTIs, among LMICs.

Self-purchasing of antibiotics for URTIs is encouraged by misconceptions about them and their usefulness in managing this condition, which for instance was seen among more than $75 \%$ of Thai students in a study pulished in 2012 (241). Common infections for non-prescription sales of antibiotics in systematic reviews include URTIs (up to $50-67 \%$ of patients) or fever $(47 \%)(43,120)$. Having said this, there have been low rates of non-prescription sales of antibiotics in some LMICs in the past. For example, in a study of community pharmacists in Zimbabwe published in 2007, the authors found that the majority of pharmacists (69\%) stated that they would never sell an antibiotic without a prescription and very few did despite high patient demand (115). However, in recent years this has changed with appreciably higher self-purchasing rates (242).

\subsection{Ongoing and potential strategies to reduce inappropriate prescribing and dispensing of antibiotics for patients with URTIs}

Multiple strategies are typically needed to reduce unnecessary prescribing and dispensing of antibiotics in ambulatory care among all key stakeholder groups including patients, parents, community pharmacists and physicians $(29,40,52,60,70,71,74,97,154,243)$. This reflects the complexity of the situation, the different beliefs of key stakeholder groups and often multiple organizations and personnel within a country involved with improving antibiotic utilization and reducing AMR rates (244). Additional strategies include influenza and conjugated pneumococcal vaccine policies, which can help reduce the risk of acute respiratory infections and any associated irrational use of antibiotics (87, 245-247).

The public, patients and children's parents are a particularly important group to improve appropriate antibiotic use in patients with URTIs given for instance the extent of self-purchasing in LMICS (Supplement Table D) as well as patient pressure on physicians to prescribe antibiotics. Studies have highlighted that patients can have an incomplete understanding of antibiotics and AMR, misconceptions about the causes of AMR, and an inappropriate belief that the overuse of antibiotics does not contribute to the development of AMR adding to physician and pharmacist pressures (56, $59,98,248)$.

Different strategies and approaches have had varying success across countries to improve the utilisation of antibiotics in ambulatory care. Successful initiatives typically target all key stakeholder groups, are usually country specific, take into account issues of culture as well as the availability, access and affordability to physicians and medicines, and are evidence based $(29,52,243)$. Given continuing concerns with AMR rates, activities and strategies to improve future prescribing and 
dispensing of antibiotics for URTIs will grow in all countries, including LMICs, as they develop and monitor their antibiotic prescribing as part of their national action plans (NAPs) $666,180,240,242$, 249-252), with 'essential medicine' policies typically associated with lower antibiotic prescribing in LMICs (119).

Various activities by key stakeholder groups, including health authorities, physicians, nurse practitioners, pharmacists and the public, and their influence are described below to inform future activities to reduce irrational antibiotic use.

\subsubsection{Health Authorities and Governments}

Health authority and government activities are particularly important to enhance rational antibiotic use. These include addressing issues of self-purchasing and pharmaceutical company promotional activities as these can have a profound impact on subsequent antibiotic utilisation $(102,119,253)$.

However, despite this importance, to date some countries have only introduced limited activities to reduce the inappropriate use of antibiotics. In Europe, this includes Poland, which resulted in Poland currently having one of the highest rates of antibiotic consumption across Europe, with utilization growing by $8.3 \%$ from 2007 to 2016 (38). In addition, some LMICs have only just published their NAPs to improve future antibiotic prescribing, including patients with URTIs, as part of agreed objectives to reduce AMR rates. Typical activities include documenting current antibiotic utilisation and resistance rates alongside planning educational, monitoring and other activities among all key stakeholder groups. Such LMICs include Botswana, Ghana (Table 2), Kenya, Kosovo, Malaysia, Nigeria, Pakistan, Swaziland, Vietnam and Zimbabwe (72, 180, 251, 252, 254-257).

Kosovo has recently launched its NAP to reduce AMR. Activities include increasing education of all key stakeholder groups, improving the monitoring and use of antibiotics as well as promoting research to improve the future use of antibiotics (72).

Malaysia has also recently implemented the Protocol of Antimicrobial Stewardship (AMS) Program in Healthcare Facilities, together with National Antibiotic Guidelines, to improve antibiotic utilisation particularly in ambulatory care (236-238). These guidance documents should benefit clinicians and pharmacists in advocating and implementing good prescribing and dispensing practices surrounding antimicrobial use to help curb rising AMR rates and reduce healthcare costs (258-260).

In 2018, the Pakistan Global Antibiotic Resistance Partnership published a situational analysis to improve future antibiotic utilisation in Pakistan, with identified challenges including addressing current irrational prescribing and dispensing of antibiotics (254). As a result, we should see improved utilisation of antibiotics in Pakistan in the future, which is encouraging given the size of the population.

National activities have also recently started in Vietnam to improve antibiotic utilisation across sectors to reverse increasing AMR rates (261). These activities especially target current high rates of self-purchasing of antibiotics in both rural and urban communities (Supplement Table C) $(46,261$ ) building on successful targeted campaigns including greater regulatory enforcement, education and peer influence among selected private pharmacies nearly 20 years ago (262). Targeted activities include raising awareness among the public regarding AMR and the need for antibiotics especially for URTIs, as well as education of physicians through guidelines and other activities (261). The Vietnamese Ministry of Health has also recently instigated activities to improve control over the prescribing and selling of prescription medicines. This applies especially to antibiotics to reduce their irrational use given current high rates of self-purchasing in the country despite legislation. There are ongoing plans in Vietnam to instigate information technology systems across the country to connect 
online suppliers and pharmacists nationwide to track antibiotic use $(263,264)$. This builds on activities among a number of countries (Table 2).

In sub-Saharan Africa, The National Action Plan on AMR for Nigeria (2017-22) was launched in 2017 based on the "One Health" approach. The country has further committed itself to reducing AMR rates including enrolling in the Global Antimicrobial Resistance Surveillance System (GLASS) (265). Similarly, Swaziland (now the Kingdom of Eswatini) has recently launched its strategy to improve antibiotic utilisation and reduce AMR rates (256). Encouragingly, recent studies have shown that antimicrobial stewardship programmes (ASPs) have helped improve the appropriate use of antibiotics in the Kingdom, providing direction for the future (266). National activities are also just starting in Zambia to reduce AMR rates following concerns with the extent of self-purchasing of antibiotics in ambulatory care (Supplement Table C) as well as concerns with the lack of ASPs in key sectors with suggested programmes to address this $(91,267-269)$.

There are also planned activities in Botswana and Namibia to develop pertinent quality indicators for assessing the quality of prescribing of antibiotics in ambulatory care given concerns with the WHO/ INRUD (International Network for the Rational Use of Drugs) indicators as well as concerns with the extent of prescribing of antibiotics for URTIs among private general practitioners in Botswana (180, $232,270,271)$. This builds on discussions of possible quality indicators to influence future prescribing of antibiotics in other LMICs (272). Adherence to current guidelines is seen as a better predictor of the quality of prescribing of antibiotics than current WHO/ INRUD criteria (271). Encouragingly in Namibia, whilst patients and parents regularly self-medicate for acute respiratory infections including the common cold and influenza for themselves and their children, this was typically with cold/ flu medication, paracetamol and decongestants, rather than antibiotics. This is helped by regulations banning the self-purchasing of antibiotics among community pharmacies in Namibia and the regular monitoring of community pharmacies (Table 4) $(182,273)$.

In LMICs where there are high rates of self-purchasing (Supplement Table C), the overuse of antibiotics also needs to be addressed through government and other activities. This includes a combination of increased public awareness, improved healthcare professional training, legislation and enforcement, as well as greater monitoring of antimicrobial use and resistance patterns (45, 274,275 ). Board certified courses could also be instigated to adequately train pharmacists (and where relevant other health professionals such as Physician Associates or Advanced Practice nurses) to prescribe antibiotics where appropriate, especially in very rural outlying areas.

Several countries have introduced multiple initiatives over many years to improve the use of antibiotics especially for URTIs providing guidance to others. This includes instigating ASPs in ambulatory care $(276,277)$. A number of Governments and health authorities, including European Health Authorities, have been particularly active over a number of years (Table 2), with recent research contrasting different approaches and activities between countries to provide future guidance (244). There are also examples of government activities among LMICs outside of Europe to reduce the irrational use of antibiotics especially for URTIs, again providing guidance to others (Table 2). 
Table 2: Activities among European countries and LMICs outside of Europe to improve the utilisation of antibiotics in ambulatory care especially for respiratory tract infections and outcomes where known

\begin{tabular}{|c|c|}
\hline Country & Activities \\
\hline \multicolumn{2}{|c|}{ High income European countries } \\
\hline Germany & $\begin{array}{l}\text { - Germany has undertaken a number of activities in recent years to improve the } \\
\text { utilisation of antibiotics in both hospitals and ambulatory care, including patients } \\
\text { with respiratory tract infections. } \\
\text { - This includes developing antimicrobial stewardship programmes and raising } \\
\text { public awareness, as well as investing in research to develop new antibiotics (244, } \\
278,279) \\
\text { - These activities are ongoing }\end{array}$ \\
\hline Slovenia & $\begin{array}{l}\text { - Multiple activities among all key stakeholder groups, including regular } \\
\text { educational activities among physicians, quality targets, prescribing restrictions } \\
\text { for amoxicillin/ clavulanic acid, cephalosporins, macrolides and the } \\
\text { fluoroquinolones, as well as patient education activities aimed at re-enforcing } \\
\text { that most infections in ambulatory care such as URTIs are viral in origin, } \\
\text { appreciably reduced antibiotic utilisation in recent years in Slovenia (40) } \\
\text { - Overall, antibiotic utilisation decreased by } 31 \% \text { between } 1999 \text { and } 2012 \text { through } \\
\text { these multiple initiatives }\end{array}$ \\
\hline Swe & $\begin{array}{l}\text { - Sweden has been particularly active over a number of years to improve antibiotic } \\
\text { prescribing and reduce AMR (280) } \\
\text { - The multiple initiatives, which included educational initiatives among physicians, } \\
\text { academic detailing, guidelines including diagnostic criteria for each condition and } \\
\text { an analysis of the risk and benefits of antibiotics, instigating local multidisciplinary } \\
\text { groups discussing antibiotic prescribing, monitoring antibiotic prescribing and } \\
\text { resistance rates including quality targets, patient education, and susceptibility } \\
\text { testing, reduced antibiotic prescribing in ambulatory care, including primary care, } \\
\text { by } 43 \% \text { between } 1992 \text { and } 2016 \text {, whilst among children } 4 \text { years or under the } \\
\text { prescribing of antibiotics including those for URTIs decreased by } 73 \% \text { (280) } \\
\text { - Overall, the prescribing of antibiotics for patients with URTIs in ambulatory care } \\
\text { in Sweden decreased from } 40.5 \% \text { in } 2008 \text { to } 24.9 \% \text { in } 2013 \text {, and continues to fall } \\
\text { further (79) } \\
\text { - As a result of these multiple initiatives, Sweden has one of the lowest rates of } \\
\text { antibiotic utilisation in Europe (281) }\end{array}$ \\
\hline $\begin{array}{l}\text { United } \\
\text { Kingdom } \\
\text { including } \\
\text { England a } \\
\text { Scotland }\end{array}$ & $\begin{array}{l}\text { - Scotland has introduced a number of national and regional initiatives in recent } \\
\text { years to improve antibiotic utilisation in ambulatory care including patients with } \\
\text { URTIs. These centre on the instigation of the Scottish Antimicrobial Prescribing } \\
\text { Group (SAPG) in } 2008 \text { to help implement the recommendations of the Scottish } \\
\text { Management of Antimicrobial Resistance Action Plan (ScotMARAP) (282) } \\
\text { - Activities included the development of quality indicators and prescribing } \\
\text { guidelines incorporating measures to reduce the prescribing of quinolones (282) } \\
\text { - Prescribing guidance based on template from Public Health England is currently } \\
\text { being used in all Scottish Health Boards (Regions) to improve antibiotic } \\
\text { prescribing including URTIs ( } 283-285 \text { ) } \\
\text { - In Scotland, the number of prescriptions for antibiotics (items/ } 1000 \text { patients/ } \\
\text { day) decreased by } 7.8 \% \text { between } 2013 \text { and } 2017 \text { following multiple activities } \\
\text { (286) } \\
\text { Multiple strategies generally throughout the UK resulted in } 6.5 \% \text { fewer } \\
\text { prescriptions for systemic antibiotics in ambulatory care in } 2014 / 2015 \text { versus }\end{array}$ \\
\hline
\end{tabular}




\begin{tabular}{|c|c|}
\hline & $\begin{array}{l}\text { 2012-2013, with } 57.5 \% \text { of GP practices achieving the national quality indicator of } \\
\text { a minimum acceptable reduction in antibiotic use ( } 287 \text { ) } \\
\text { - More recent reports showed that the prescribing of antibiotics in ambulatory } \\
\text { care in England fell by } 13.2 \% \text { in the past } 5 \text { years from } 2013 \text { levels (288) } \\
\text { - Guidance regarding the management of URTIs, as well as other strategies to } \\
\text { improve antibiotic prescribing including patient education, has also been } \\
\text { introduced in the UK }(287,289-292) \text {. These activities resulted in a significant } \\
\text { reduction in the prescribing of cephalosporins and fluoroquinolones in England in } \\
2013 \text { versus } 2005 \text { ( } 287) \\
\text { - Recent targets for GPs in the UK include reducing their rate of antibiotic } \\
\text { prescribing by } 2 \% \text { per year or more through co-ordinated activities over the next } \\
\text { five years (293). This includes patients with URTIs }\end{array}$ \\
\hline \multicolumn{2}{|c|}{ LMICs including those in and outside of Europe } \\
\hline Albania & $\begin{array}{l}\text { - Independent studies have shown high rates of self-purchasing of antibiotics in } \\
\text { Albania ( } 78 \% \text { - } 80 \% \text { ) despite legislation banning this, exacerbated by one third of } \\
\text { Albanians not covered by health insurance (294) } \\
\text { - These concerns, coupled with variable knowledge among pharmacists regarding } \\
\text { antibiotics and AMR ( } 294,295) \text {, resulted in a small pilot campaign in } 2016 \text { / } 2017 \\
\text { targeting pharmacists and patients in community pharmacies to reduce } \\
\text { inappropriate use of antibiotics especially for URTIs (295). Activities included a } \\
\text { poster with advice on how to appropriately use and dispense antibiotics } \\
\text { - Follow-up of the campaign is ongoing to assess the influence of such activities } \\
\text { with potential roll out across Albania } \\
\text { More recently (2018), given concerns including the dispensing antibiotics without } \\
\text { a prescription, the Albanian Ministry of Health established a task force to improve } \\
\text { control over the dispensing of medicines over the counter without a prescription } \\
\text { among community pharmacies ( } 295-297) \\
\text { - Preliminary results suggest that over } 20 \% \text { of the pharmacies inspected to date in } \\
\text { Albania had been fined for selling medicines without a prescription. Overall, in } \\
\text { the first months of implementation of the new measures, } 115 \text { community } \\
\text { pharmacies had been inspected with } 20 \text { fined for dispensing a medicine without a } \\
\text { prescription } \\
\text { This MoH initiative is ongoing, with pharmacies increasingly aware of the need to } \\
\text { only dispense medicines with a prescription else they will be fined. The impact of } \\
\text { these additional measures is also being monitored in case further initiatives are } \\
\text { needed to further improve the management of patients with, for instance, } \\
\text { respiratory tract infections in community pharmacies }\end{array}$ \\
\hline Azerbaijan & $\begin{array}{l}\text { - Multiple activities in Azerbaijan in recent years included regular national } \\
\text { initiatives to educate physicians not to prescribe antibiotics for likely viral } \\
\text { infections including URTIs, and guidelines recommending penicillins first line for } \\
\text { URTIs if an antibiotic is needed } \\
\text { - Other activities included reinforcing in pharmacies that it is illegal to sell } \\
\text { antibiotics without a prescription. In addition, educational campaigns in } \\
\text { pharmacies that most infections seen such as URTIs are viral in origin and do not } \\
\text { require an antibiotic (70) } \\
\text { - These multiple activities resulted in a significant reduction in antibiotic utilization } \\
\text { in Azerbaijan from } 17.1 \text { DDDs (DDDs/ } 1000 \text { inhabitants / day) in } 2011 \text { to } 8.02 \text { DIDs } \\
\text { in 2015, which was the lowest utilisation level compared with similar countries } \\
\text { - In addition, an overall low utilisation of co-amoxiclav, macrolides, cephalosporins } \\
\text { and the fluoroquinolones compared with similar countries (70) }\end{array}$ \\
\hline Brazil and & - In Mexico and Brazil, national restrictions were placed on the self-purchasing of \\
\hline
\end{tabular}




\begin{tabular}{|c|c|}
\hline Mexico & $\begin{array}{l}\text { antibiotics in } 2010 \text {, although a prescription was always a requirement for } \\
\text { antibiotics to be dispensed among public pharmacies in Brazil }(56,74,298) \\
\text { - There was a reduction in penicillin use among private pharmacies in Mexico after } \\
\text { this initiative, with a more limited reduction in Brazil }(298,299) \\
\text { - Further details about the impact of these initiatives are contained in Table } 4\end{array}$ \\
\hline Chile & $\begin{array}{l}\text { - Chile was one of the first countries in Latin America to introduce greater } \\
\text { enforcement of the law to reduce self purchasing of antibiotics in } 1999 \text { following } \\
\text { concerns with increasing antimicrobial consumption and AMR, with its impact } \\
\text { enhanced by antibiotics being removed from the list of medicines having sales } \\
\text { incentives in pharmacies (300) } \\
\text { - Antimicrobial consumption decreased from } 12.3 \text { DIDs before the intervention to } \\
8.5 \text { DID just after the enforcement (in 2000) aided also by the instigation of public } \\
\text { information campaigns before and during greater enforcement of the regulations } \\
(298,300 \text { ) } \\
\text { - However, there has been a slow increase in antimicrobial utilisation since } 2002 \\
\text { suggesting that the effects of such interventions wear off unless utilization is } \\
\text { monitored and further initiatives introduced when and where pertinent }\end{array}$ \\
\hline China & $\begin{array}{l}\text { - The government launched a national Action Plan in } 2011 \text { targeting antibiotic } \\
\text { misuse in public hospitals where most antibiotics are dispensed in China (62) } \\
\text { - The plan emphasized the key roles for DTCs and clinical pharmacists in developing } \\
\text { formularies and monitoring prescribing against current guidance as well as } \\
\text { developing and implementing antibiotic stewardship programmes to improve } \\
\text { out-patient (as well as in-patient) use of antibiotics including patients with URTIs } \\
\text { - The multiple activities reduced out-patient utilisation of antibiotics by } 12.9 \% \text { by } \\
\text { the end of } 2014 \text {, with a greater reduction in the in-patient use of antibiotics (62) }\end{array}$ \\
\hline Ghana & $\begin{array}{l}\text { - The Ministry of Health in Ghana recently launched a 5-year NAP, with assistance } \\
\text { from the Fleming Fund in United Kingdom, to cover the period } 2017 \text { to } 2021 \text { (301, } \\
\text { 302) } \\
\text { - The NAP covers several areas including improving awareness and knowledge of } \\
\text { AMR, providing evidence-based knowledge to reduce the burden of AMR to } \\
\text { reduce inappropriate prescribing and dispensing of antibiotics, establishing a } \\
\text { surveillance system for antimicrobial consumption, optimizing the use } \\
\text { antimicrobials in humans and creating an enabling environment for sustainable } \\
\text { investment in AMR reduction } \\
\text { - As part of this, greater enforcement of software programmes in community } \\
\text { pharmacies as a means of tracking irrational dispensing and the use of non- } \\
\text { prescribed antibiotics ( } 301 \text { ) } \\
\text { - The findings from these various initiatives are being followed up to see if } \\
\text { additional activities are need to further reduce inappropriate dispensing of } \\
\text { antibiotics in community pharmacies }\end{array}$ \\
\hline Kosovo & $\begin{array}{l}\text { - The Ministry of Health in December } 2018 \text { approved a new national action plan for } \\
\text { - TMR incorporating different activities for all key stakeholder groups (72) } \\
\text { There are also appreciable ongoing activities including workshops, social media } \\
\text { activities, and television advertisements, to raise awareness of the consequences } \\
\text { of inappropriate antibiotic use including antibiotics for patients with URTIs } \\
\text { - The Ministry of Health is also currently revising the essential medicines list } \\
\text { including available antibiotics } \\
\text { - There is also currently an ongoing debate in the Kosovo Medicines Agency and } \\
\text { the Ministry of Health as to whether two prescriptions should be given for } \\
\text { antibiotics, one copy of which will be saved in the pharmacy for } 5 \text { years } \\
\text { (comparable to narcotics) to help monitor physician prescribing practices }\end{array}$ \\
\hline
\end{tabular}




\begin{tabular}{|c|c|}
\hline & $\begin{array}{l}\text { - Alongside this, continual monitoring of annual antibiotic consumption as part of } \\
\text { the WHO European Antimicrobial monitoring group }(274,303) \text { building on } \\
\text { activities in other disease areas (304) } \\
\text { - These activities are being followed up to see if additional measures are needed to } \\
\text { further reduce inappropriate antibiotic utilisation for infections including URTIs }\end{array}$ \\
\hline $\begin{array}{l}\text { Republic of } \\
\text { Srpska }\end{array}$ & $\begin{array}{l}\text { - In 2010, } 58 \% \text { of pharmacies sold an antibiotic for a self-diagnosed URTI despite } \\
\text { legislation banning this (305) } \\
\text { - Consequently, the Republic of Srpska has been active over a number of years to } \\
\text { improve the prescribing and dispensing of antibiotics in ambulatory care including } \\
\text { patients with URTIs ( } 71 \text { ) } \\
\text { - Activities included diagnostic and prescribing advice for physicians, a limited list } \\
\text { of reimbursed antibiotics, continual education of pharmacists and pharmacist } \\
\text { technicians as well as published guidelines for pharmacy personnel to successfully } \\
\text { treat URTIs patients with over-the-counter medicines or refer them to a GP (71) } \\
\text { - In addition, continual inspections by Republic of Srpska Inspectorate personnel } \\
\text { since by law antibiotics are restricted to prescription only medicines in the } \\
\text { Republic } \\
\text { - These combined activities resulted in the Republic having one of the lowest } \\
\text { utilisations of antibiotics in recent years compared with similar countries as well } \\
\text { as an appreciable reduction in the self-purchasing of antibiotics in recent years } \\
\text { (71, 306) }\end{array}$ \\
\hline Sout & $\begin{array}{l}\text { - South Africa has also been active with developing national action plans to combat } \\
\text { rising AMR rates for a number of years (307, 308), providing guidance to other } \\
\text { sub-Saharan African countries } \\
\text { - Activities include the development of the National Department of Health } \\
\text { Antimicrobial Resistance National Strategy Framework, 2014-2024 building on } \\
\text { the WHO global strategy to contain and reduce rising AMR rates (250, 307). As } \\
\text { part of this, ongoing programmes within hospitals in South Africa have instigated } \\
\text { ASPs to reduce AMR rates, with published guidance on ASPs to help instigate such } \\
\text { programmes (309-311) } \\
\text { - In the community, there are also ongoing programmes to assess prescribing } \\
\text { against agreed guidance given concerns with, for instance, the extent of antibiotic } \\
\text { prescribing for URTIs (312). This includes promoting community pharmacists to } \\
\text { help drive ASPs forward to improve the utilisation of antibiotics for respiratory } \\
\text { tract infections in ambulatory care (159) } \\
\text { - Such initiatives are likely to grow to further improve the prescribing of antibiotics } \\
\text { in ambulatory care across all sectors, with the South African guidelines regularly } \\
\text { updated (250, 313) } \\
\text { - In addition, community pharmacists can also recommend alternative treatments } \\
\text { for minor URTIs and reassure patients of the inappropriateness of antibiotics. } \\
\text { They can also uphold the law and not permit self-purchasing of antibiotics as well } \\
\text { as advise patients on any possible side-effects of any antibiotic prescribed to } \\
\text { enhance adherence rates (307) } \\
\text { Educational activities are also being encouraged in pharmacy and medical schools } \\
\text { and wider as part of ongoing programmes to improve their knowledge about } \\
\text { antibiotics and AMR ( } 50,314,315 \text { ) } \\
\text { Ongoing research programmes are monitoring the impact of these multiple } \\
\text { activities to introduce further activities and initiatives if needed }\end{array}$ \\
\hline Turkey & $\begin{array}{l}\text { - The Ministry of Health in Turkey recently implemented an electronic prescription } \\
\text { system to track prescription data across the country from production to } \\
\text { dispensing as well as provide feedback to physicians }(274,316)\end{array}$ \\
\hline
\end{tabular}




\begin{tabular}{|l|ll|}
\hline & $\begin{array}{l}\text { This was in line with the } 2014 \text { - } 2017 \text { National Action Plan to enhance the } \\
\text { appropriate use of antibiotics in Turkey given current high utilisation rates } \\
\text { compared with other European countries and AMR (303) } \\
\text { - The regulations reducing future self-purchasing of antibiotics include potential } \\
\text { fines for pharmacists following abuse aided by the "track and trace" system } \\
\text { - It is envisaged that future studies will show an appreciable decrease in self- } \\
\text { purchasing similar to expectations in Albania }\end{array}$ \\
\hline Venezuela & $\begin{array}{l}\text { In 2006, Venezuela implemented a national policy to reduce the self-purchasing } \\
\text { of three groups of antibiotics: namely macrolides, quinolones and third } \\
\text { generation cephalosporins due to concerns with their over use (300) }\end{array}$ \\
& $\begin{array}{l}\text { This though was without any public awareness campaigns } \\
\text { Overall, there was no change in their utilisation patterns as 'enforcement' was } \\
\text { only made via formal government publications and not followed up with any } \\
\text { increased pharmacy supervision or any pharmacy closures/ financial sanctions for } \\
\text { non-compliance (298, 300) }\end{array}$ \\
\hline
\end{tabular}

NB: $A M R=$ Antimicrobial Resistance; ASP = antimicrobial stewardship programmes; DDD = defined daily dose; DTCs = Drug and Therapeutic Committees; MoH: Ministry of Health; URTIs = Upper Respiratory Tract Infections

\subsubsection{Physicians}

Many programmes have been instigated across countries to try and reduce unnecessary antibiotic prescribing among ambulatory care physicians, especially for suspected viral infections $(78,85,88$, $151,317)$. However, there is no one universal programme, and programmes typically need to be tailored to the different situations with different governance structures $(78,85,244)$. A team approach with consistent advice, improved communication between family doctors or general practitioners (GPs), patients and children's parents, including addressing current perceptions and demedicalising self-limiting viral infections, is seen as critical to improve antibiotic prescribing among family doctors for respiratory tract infections $(152,156,202,208,318)$. Seeking ways to improve guideline adherence is also seen as important (271). Education initiatives for doctors starting at medical school may be necessary in LMICs where there are concerns with current training and its impact on reducing inappropriate prescribing of antibiotics $(48,50,315,319-327)$.

Improving communication between family doctors and patients should help address concerns that physicians want to help their patients, and tend to over-estimate patients' expectations regarding their wish to be prescribed an antibiotic for their URTI $(21,153,156)$. Physicians are also more likely to prescribe an antibiotic if they feel under pressure $(108,328,329)$.

A number of approaches to improve the use of antibiotics in ambulatory care in high- as well as highmiddle income countries have been described and reviewed by Dyar et al (85). These are of relevance to LMICs as the care of patients with URTIs increasingly moves to physicians. The approaches can be broken down into educational activities including (i) academic detailing with varying degrees of success and evidence, (ii) guidelines and clinical decision support systems, (iii) initiatives to delay the prescribing of antibiotics especially for URTIs, (iv) special prescription forms highlighting the importance of antibiotics in healthcare, ( $v$ ) having posters in surgeries emphasizing the commitment of family doctors to reducing unnecessary prescribing of antibiotics, (vi) instigating point of care testing to determine the likely cause of the infection, (vii) instigating quality indicators (QIs) and monitoring performance against these, (vii) undertaking regular auditing of prescribing and feedback, (viii) restricting the number and prescribing of certain antibiotics, (ix) separating prescribing and dispensing, $(\mathrm{x}$ ) and restricting pharmaceutical company activities (85). 
Restricting or addressing inappropriate pharmaceutical company activities is particularly important in LMICs, where companies can be the principal source of physician education regarding antibiotics $(330,331)$. Selective point-of-care testing is seen as potentially beneficial in patients with URTIs $(101,332)$, and decision support systems have been shown to reduce the overuse of antibiotics in ambulatory care settings (333). Social norm feedback among physicians can also appreciably reduce antibiotic prescribing in ambulatory care (334).

Several initiatives have been introduced across countries over the years to reduce inappropriate prescribing of antibiotics among physicians especially for patients with URTIs in both high income countries as well as LMICs $(29,76,85,151,335)$. The impact of some of these for high income countries are contained in the Supplementary material for potential reference and adaptation to LMICs (Supplement Table E).

Table 3 contains the impact of different interventions among physicians in ambulatory care in LMICs to reduce unnecessary antibiotic prescribing. These may not always be RTI or URTI specific although typically multiple interventions again appear to have the greatest impact (29). The number of published papers in LMICs is more limited compared to high income countries due to their paucity. Sun et al (2015) showed though that there can be appreciable differences in physician beliefs and actual prescribing practices. Whilst most physicians in rural areas of Shandong Province had attended further training on antibiotic use since the beginning of their medical practice as a doctor, and only $2 \%$ said they would prescribe antibiotics for patient with a common cold, the reality was very different (336). In fact, $55 \%$ of the physicians surveyed included an antibiotic prescription when treating patients with a common cold (336). In addition, Esmaily (2010) showed no significant improvements in antibiotic prescribing practices after an outcome-based educational approach among ambulatory physicians in Iran; however, overall there was an appreciable reduction in the number of medicines prescribed (337). Mobile technologies with clinical algorithms can also improve the management of childhood illness leading to an appreciable reduction in antibiotic utilisation (338). This is a potential approach for the future in LMICs given the wide use of mobile technologies across countries $(339,340)$. 
Table 3: Initiatives to improve antibiotic utilisation among physicians in LMICs

\begin{tabular}{|c|c|}
\hline Country & Intervention and impact \\
\hline China & $\begin{array}{l}\text { Study one (2014) (341) } \\
\text { - In Ningxia Province a matched-pair cluster-randomized study was undertaken } \\
\text { to evaluate the effects of capitation with pay-for-performance on primary care } \\
\text { providers' antibiotic prescribing practices, health spending, outpatient visit } \\
\text { volume, and patient satisfaction } \\
\text { - This intervention resulted in approximately } 15 \% \text { reduction in antibiotic } \\
\text { prescriptions and a small reduction in total spending per visit } \\
\text { Study Two (2019) (88) } \\
\text { - Cluster randomised study among } 14 \text { primary healthcare facilities in rural China } \\
\text { - } \quad \text { An intervention comprising clinical guidelines, monthly prescribing review } \\
\text { meetings, doctor-patient communication skills training, and education } \\
\text { materials for caregivers, appreciably reduced antibiotic prescription rates (ABR) } \\
\text { in children with URTIs } \\
\text { - There was a } 49 \% \text { reduction in ABR after } 6 \text { months in the intervention arm } \\
\text { having adjusted for patient and prescribing doctor covariates } \\
\text { - The reductions persisted after } 18 \text { months but at a lower rate (-36\%) } \\
\text { Factors sustaining the reduction included physicians' improved knowledge and } \\
\text { communication skills combined with focused prescription review meetings }\end{array}$ \\
\hline Nepal & $\begin{array}{l}\text { Study One (2006) (342) } \\
\text { - } 7 \text { health posts and } 33 \text { subhealth posts were stratified by type with health } \\
\text { workers from the intervention facilities receiving } 5 \text { days training on the adapted } \\
\text { Practical Approach to Lung Health (PAL) guidelines and their use } \\
\text { - } \quad \text { Appropriate prescribing of antibiotics and adherence to guidelines improved; } \\
\text { however, this was not statistically significant unlike other areas such as } \\
\text { polypharmacy and generic prescribing rates } \\
\text { Study Two (2009) (343) } \\
\text { - Supervision/ monitoring involving periodic visits by district supervisors to } 41 \\
\text { primary health care (PHC) facilities. The intervention included small-group } \\
\text { training among prescribers followed by peer-group discussions alongside self- } \\
\text { assessment of the data presented } \\
\text { - In children under five, there was a significant improvement in use of } \\
\text { antimicrobials in diarrhoea and in URTIs without pneumonia }\end{array}$ \\
\hline Sudan (344) & $\begin{array}{l}\text { Twenty health centers in Khartoum Dtate were randomly assigned to receive } \\
\text { either (a) no intervention; (b) audit and feedback; (c) audit and feedback + } \\
\text { seminar; or ( } d \text { ) audit and feedback + academic detailing } \\
\text { The targeted interventions involving audit and feedback combined with } \\
\text { academic detailing reduced the mean number of physician encounters with an } \\
\text { antibiotic prescribed by } 6.3 \text { and } 7.7(p<0.001 \text { ) at } 1 \text { and } 3 \text { months post- } \\
\text { intervention, respectively. The mean number of encounters where antibiotics } \\
\text { were inappropriatetly prescribed were also significantly reduced post } \\
\text { intervention ( }<<0.001) \\
\text { - } \text { Reducing the number of activities reduced the overall impact }\end{array}$ \\
\hline
\end{tabular}

Nurse specialists can also treat patients at primary healthcare centres (PHCS) in many LMICs due to the shortage of physicians, although this is not always the case $(69,240,313)$. Similar approaches to 
those for physicians would be applicable in this situation to reduce inappropriate use of antibiotics in patients with URTIs (119).

\subsubsection{QIs to Improve Antibiotic Prescribing in Ambulatory Care}

A variety of Qls have been developed over the years to improve antibiotic prescribing in ambulatory care especially for patients with URTIs. Their development has involved a number of groups including the WHO, ECDC, and ESAC (274, 281, 345-347). Qls can range from general Qls based on the class of antibiotic prescribed (Supplement Box A) to more specific indicators based on actual prescribing. Slovenia has also instigated several QIs to enhance the prescribing of antibiotics, including those for URTIs (Supplement Box B). The general Qls (Supplement Box A) reflect the concerns of the WHO and others regarding the over use of co-amoxiclav, fluoroquinolones, thirdand fourth-generation cephalosporins, macrolides and glycopeptides. Addressing the misuse of these antibiotics is seen as the highest priority to improve future prescribing and dispensing of antibiotics in ambulatory care ambulatory care $(274,347)$.

Specific indicators for the prescribing of antibiotics to children for URTIs include the proportion of amoxicillin users (amoxicillin index) and the ratio of amoxicillin to broad-spectrum penicillins, cephalosporins and macrolides $(A / B$ ratio) $(21,229)$. Such indicators are included in Slovenia's QIs (Supplement Box B). Specific Qls also include adherence to guidelines. Adherence to guidelines has been found to better represent the quality of prescribing in ambulatory care versus current $\mathrm{WHO} /$ INRUD criteria $(271,313,335,348)$. However, it is important that there is only one national reference guideline since where multiple guidelines exist contradictions can occur (236). Guidelines should be readily available and combined with educational inputs and auditing of antibiotic prescribing to reduce inappropriate use $(57,250,270,313,335,349)$. Regular updates of antibiotic guidelines are also essential to enhance their utilisation, and updates should be rapidly disseminated to achieve agreed goals. This is being achieved in South Africa through mobile technologies (250), providing guidance to other LMICs. However as shown in New Zealand, this has to be accompanied by other interventions to enhance adherence to guidelines (340).

The HEDIS (Healthcare Effectiveness Data and Information Set) datasets in the US also include specific indicators to improve the management of patients with URTIs, again providing direction to other countries (350) (Supplement Box C).

More recently, an international multidisciplinary group consolidated potential Qls for patients in ambulatory care particularly those with respiratory tract infections. These included both structure and process measures (Box 1) (351). 
Box 1: Updated Quality Indicators In Ambulatory Care Including Those For Patients With Respiratory Tract Infections (351)

- Antibiotics should be prescribed for (most) bacterial infections (e.g. acute pneumonia, urinary tract infections)

- Antibiotics should not be prescribed for viral infections or (most) self-limiting bacterial infections (e.g. acute bronchitis, influenza, acute otitis media in children $>2$ years old)

- Ambulatory care patients should receive antibiotic therapy compliant with agreed guidelines; this includes, but is not limited to, indication, choice of the antibiotic, duration, dose and timing

- Some antibiotics should rarely be prescribed

- Acute upper respiratory infections and bronchitis should not be treated with antibiotics within the first 3 days, unless there is documented indication for treatment

- Ambulatory care patients with acute tonsillitis/pharyngitis should undergo a group A streptococcal diagnostic test to decide whether or not they should receive antibiotics

- Ambulatory care patients with an acute tonsillitis/pharyngitis and positive group A streptococcal diagnostic test should be treated with antibiotics

- Antibiotics for an acute tonsillitis/pharyngitis should be withheld, discontinued or not prescribed if a patient presents a diagnostic test (rapid antigen test or throat culture) negative for group A streptococci

- Prescribed antibiotics should be chosen from an essential list/agreed formulary

- Possible contraindications should be taken into account when antibiotics are prescribed

- Antibiotics from the list of essential antibiotics should be available in health facilities that dispense antibiotics

- Key antibiotics should not be out of stock in health facilities that dispense antibiotics

- Health facilities should keep adequate records of dispensed key antibiotics

- A copy of the essential antibiotics list should be available in health facilities

- Standard antibiotic treatment guidelines should be available in health facilities

- Health facilities should have access to the Summary of Product Characteristics of prescribed antibiotics, written in a local language

\subsubsection{Community Pharmacists}

Community pharmacists are often the first healthcare professional that patients consult with regarding URTIs such as a cold or cough. This is because they are typically more accessible than physicians, especially in rural communities (155). Other factors include long waiting times to see a physician or nurse in PHCs in LMICs, losing income because of loss of work, as well as possibly having to travel long distances to access healthcare professionals in PHCs along with the associated costs $(69,134,306,352-356)$.

The limited number of physicians in several LMICs, coupled with opportunities for training pharmacists, increases their role in managing most URTIs. As a result, there are increasing calls for community pharmacists to lead local ASPs in ambulatory care to reduce unnecessary prescribing and dispensing of antibiotics (159).

Consequently, pharmacists are increasingly seen as a key stakeholder group to improve antibiotic utilization in LMICs, especially when patients cannot afford to see both a physician and purchase pertinent medication (307, 353, 357-359), and given the extent of self-purchasing of antibiotics seen in a number of LMICs (Supplement Table D). The importance of pharmacists is highlighted by activities promulgated by FIP (International Federation of Pharmacists) and the WHO $(360,361)$ (Box 2). 
- Pharmacists are an essential player in the health system and, whilst they take an increasing role in providing relevant information to patients, there is room for improvement.

- Pharmacists should encourage the prudent use of antibiotics, taking full advantage of their position as they are often the first contact patients have with the healthcare system and are increasingly seen as an effective liaison between prescribers and patients. This includes patients being appropriately counselled on the need for and use of antibiotics, particularly for URTIs to reduce adverse effects and AMR, and, for URTIs such as a common cold or a sore throat, recommending other treatments.

- When dispensing antibiotics, patients should be given proper counselling and provided with appropriate written information.

- Pharmacists should encourage patients to comply with the full prescribed or dispensed regimen when dispensed and should become actively involved in promoting hygiene and infection control across healthcare settings.

GRIP suggest similar activities including seeking to restrict non-prescription sales of antibiotics, providing data on the scale of the problem, provision of continuing professional development/training where this is currently lacking, outlining the business benefits of patient satisfaction, and the provision of guidelines and patient education material where this does not exist $(158,159)$.

In some LMICs, concerns have been raised regarding pharmacists', pharmacist assistant's and pharmacy students' level of knowledge on antibiotics and AMR (52, 141, 242, 295, 354, 362-368); however this is not universal (364). This may reflect a greater priority for enhancing sales in pharmacies rather than worrying about professional behaviour $(128,141,143)$. As a result, there is a need to ensure good knowledge about antibiotics and AMR development in the teaching curriculum and for pharmacists and their assistants, with regular community practice follow-up post qualification $(46,362,369)$. Education about ASPs is also important, building on the potential role for pharmacists in leading ASPs in the community in the future having overcome current boundaries and barriers $(143,159,314,370)$. In addition, increasing the availability of pragmatic guidelines could help pharmacists and their assistants enhance the appropriate management of patients with URTIs $(306,364)$.

Other potential activities include instigating and monitoring the impact of measures to restrict the sales of antibiotics without a prescription as seen in Albania, the Republic of Srpska, Ghana and Turkey (Table 2). However, these measures have had variable success $(74,134,242,298,299,369$, $371)$, which may reflect concerns about their implementation, coupled with concerns about loss of income (128). Any measure introduced must be carefully thought through in rural LMIC communities where there is a scarcity of physicians, and community pharmacists may be the only healthcare professional that patients can readily access.

Table 4 provides a summary of some of the activities among LMICs to try and reduce the extent of self-purchasing of antibiotics especially for URTIs, and their impact, providing future direction. This builds on Table 2 . 
Table 4: Summary examples of initiatives to reduce self-purchasing of antibiotics in pharmacies

\begin{tabular}{|c|c|}
\hline untry & \\
\hline $\begin{array}{ll}\text { Brazil and } \\
\text { Mexico }\end{array}$ & 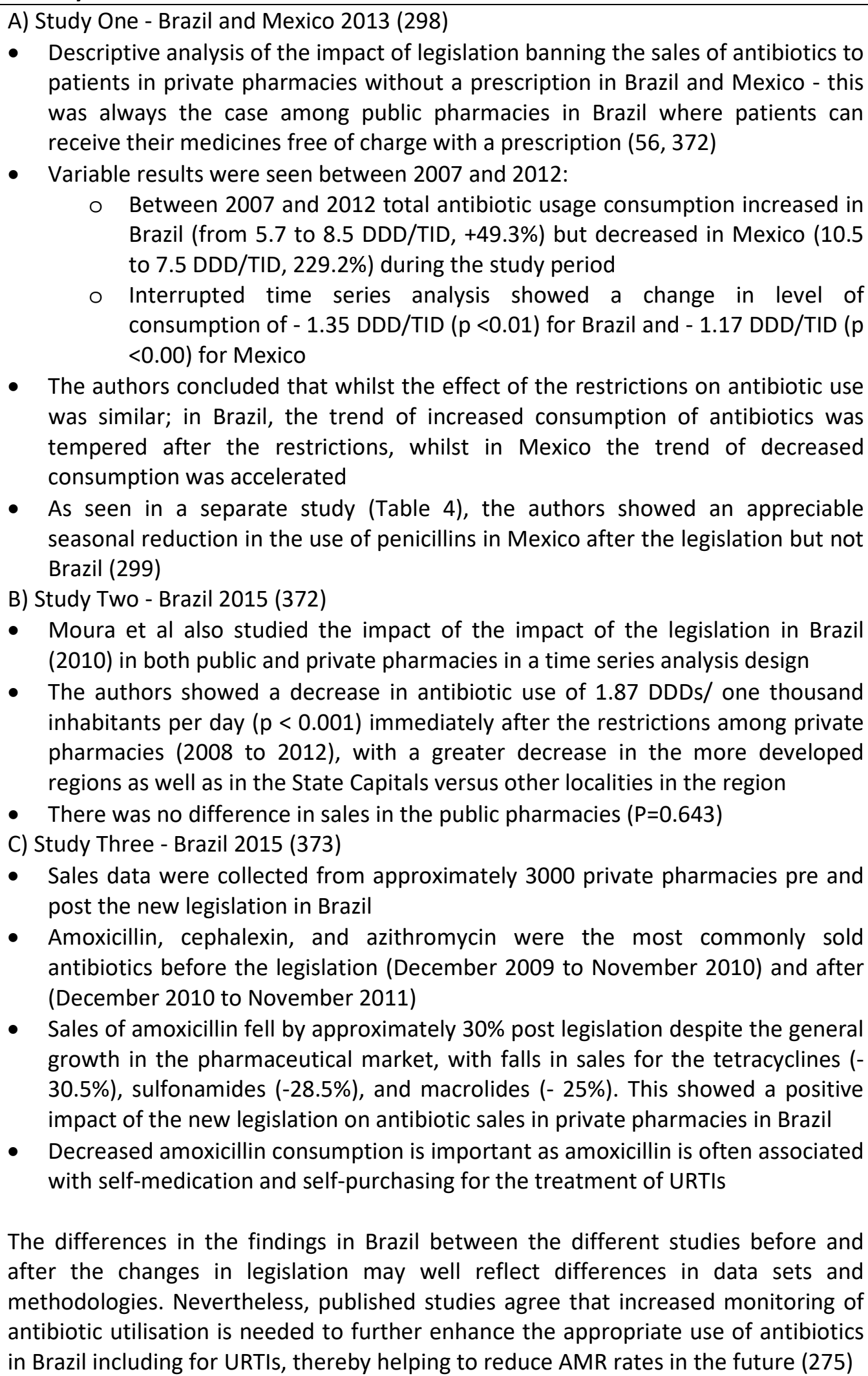 \\
\hline $\begin{array}{ll}\text { Kenya } & - \\
2018(358)\end{array}$ & $\begin{array}{l}\text { - Cross-sectional study among selected pharmacies in Nairobi } \\
\text { - Monitoring of antibiotic dispensing among pharmacies allied to the University of } \\
\text { Nairobi showed a low level of dispensing of antibiotics without a prescription, }\end{array}$ \\
\hline
\end{tabular}




\begin{tabular}{|c|c|}
\hline & $\begin{array}{l}\text { with } 94.1 \% \text { of antibiotics dispensed with a valid prescription } \\
\text { - No antibiotics were prescribed or dispensed for patients with a common cold or } \\
\text { influenza, with over-the-counter (OTC) medications such as cough and cold } \\
\text { syrups and lozenges often dispensed }\end{array}$ \\
\hline $\begin{array}{l}\text { Namibia } \\
2018 \quad(182, \\
273)\end{array}$ & $\begin{array}{l}\text { - In a survey involving } 100 \text { households in Namibia, the authors found that patients } \\
\text { regularly self-medicated for themselves or their children for acute respiratory } \\
\text { infections, including for common colds and influenza } \\
\text { - However, this was typically with cold/flu medication, paracetamol and } \\
\text { decongestants, rather than antibiotics } \\
\text { - This is helped by regulations banning the self-purchasing of antibiotics with } \\
\text { community pharmacies regularly monitored }\end{array}$ \\
\hline $\begin{array}{l}\text { Republic of } \\
\text { Srpska } 2017 \\
(305,306)\end{array}$ & $\begin{array}{l}\text { - Observational, cross-sectional study involving community pharmacists across all } \\
\text { regions to assess the influence of a series of interventions in recent years (Table } \\
\text { 2) including guidelines for pharmacists and greater enforcement of the } \\
\text { regulations banning self-purchasing of antibiotics } \\
\text { - This resulted in the self-purchasing of antibiotics for self-diagnosed URTIs } \\
\text { significantly decreasing from } 58 \% \text { to } 18.5 \% \text { among the pharmacies visited (Table } \\
\text { 2) } \\
\text { - The most common reason for not dispensing an antibiotic was that antibiotics } \\
\text { cannot be dispensed without a prescription } \\
\text { - These multiple activities are continuing to further improve the management of } \\
\text { patients with respiratory tract infections visiting pharmacies, including further } \\
\text { lowering the extent of dispensing an antibiotic without a prescription }\end{array}$ \\
\hline
\end{tabular}

NB: DDDs = defined daily dose, DD/ TID = DDDs per one thousand inhabitants per day, OTC = overthe-counter, URTI: Upper respiratory tract infection

\subsubsection{Patients and the Public}

Finally, it is vitally important to target patients and the public in any future initiative as they can put pressure on physicians, pharmacists and nurses to prescribe and dispense antibiotics for URTIs (98, $157,208,374)$. People vary in their knowledge about antibiotics and AMR; however, and they can have strong beliefs about the effectiveness of antibiotics even for viral infections $(104,137,157$, 248, 375-377).

Multifaceted approaches are typically needed to change behaviour and attitudes among patients (6, 292); however, there have been varying degrees of success $(157,160,378,379)$. Approaches include addressing issues of communication between healthcare professionals and patients during the consultation, which involves eliciting and addressing key issues including patients' beliefs concerning the effectiveness of antibiotics for URTIs $(85,202,380,381)$. Factors enhancing the success of any antibiotic awareness campaign include: (i) the use of carefully designed and simple key messages; (ii) targeting a wide audience including patients and their families as well as healthcare workers; (iii) designing key messages with all key stakeholder groups including healthcare professionals; and (iv) using mass media and social media to raise awareness. In addition, key messages should be continuously repeated to meet the needs of new parents and others $(60,157,160,382,383)$.

The success of any campaign targeting patients and the public will necessarily depend on social, cultural, and geographical factors as well as existing patterns of prescribing (61). Encouragingly, two systematic reviews report significantly reduced antibiotic prescribing with patient campaigns. McDonagh et al found that parent education reduced antibiotic prescribing for acute RTIs by $21 \%$ (151) and Cross et al (principally including high income countries in Europe and the US targeting both 
physicians and the general public) found that the majority of studies reported reductions of more than $14 \%$ in the prescribing of antibiotics for RTIs up to a maximum reduction of $30 \%$ (157).

Table $\mathrm{F}$ in the Supplementary material contains details of several patient campaigns and their influence, especially in high income countries to help inform LMICs. However, it is acknowledged that patient campaigns will be more challenging in LMICs, especially where resources and personnel are key issues (119).

Parents with lower paid employment are a particular focus for any patient campaign in LMICs as it is this population group that is most likely to seek antibiotics from pharmacists in the belief that their children will recover more quickly from their infection with an antibiotic and they will be able to have a quicker return to work (203). However, patient educational initiatives in LMICs have not yet been fully elucidated, including the costs of campaigns and their effectiveness (61). Consequently, caution is still needed.

\section{DISCUSSION AND CONCLUSION}

The irrational use of antibiotics, including their over-prescribing and self-purchasing, for the management of patients with URTIs continues to be an issue among LMICs. Such practices need to be urgently addressed to reduce rising AMR rates.

The major drivers of inappropriate prescribing and dispensing of antibiotics for RTIs include (i) variable knowledge among patients, prescribers and dispensing staff regarding antibiotics and AMR; (ii) limited knowledge regarding current antibiotic utilisation patterns and resistance rates, especially for patients with URTIs in a number of countries; (iii) lack of ASPs in ambulatory care; (iv) pressure from patients and caregivers to prescribe and/ or dispense antibiotics because of their beliefs surrounding antibiotics, $(v)$ profit motive and concerns among pharmacists coupled with a lack of enforcement of legislation banning the self-purchasing of antibiotics for URTIs where this is a concern; (vi) lower socioeconomic status in LMICs with issues of overcrowding and malnutrition; and (vii) long waiting times to see health professionals in PHCs in a number of LMICs.

Multiple strategies are needed to improve the future prescribing and dispensing of antibiotics among all key stakeholder groups for patient with URTIs. These include additional education and training for physicians where pertinent incorporating enhanced communication skills with patients, closer monitoring of the prescribing of antibiotics for URTIs, and the instigation of quality indicators. Educational initiatives are also needed where pertinent for community pharmacists along with the instigation of guidelines for patients with URTIs, greater tracking of antibiotics through the supply chain and the instigation and enforcement of policies to reduce inappropriate self-purchasing of antibiotics where pertinent. As these activities progress, rising AMR rates should start to reduce. Health education activities among patients and the public are also needed to supplement activities with physicians and pharmacists. Such activities should principally centre around communicating that URTIs are predominantly viral in origin and self-limiting; consequently, antibiotics are often inappropriate. Antibiotics can also cause side-effects as well as increase AMR rates.

Suggested strategies to improve the prescribing and dispensing of antibiotics for URTIs among LMICS are based on the findings in Section 3.4 coupled with the knowledge and practice of the multiple coauthors. These have been divided into short- and long-term initiatives (Table 5). 
Table 5: Suggested strategies (particularly In LMICs) to improve appropriate prescribing and dispensing of antibiotics for URTIs

\begin{tabular}{|c|c|}
\hline Time scale & Potential strategies \\
\hline $\begin{array}{l}\text { Short term - } \\
\text { including a } \\
\text { situational analysis } \\
\text { where appropriate }\end{array}$ &  \\
\hline
\end{tabular}




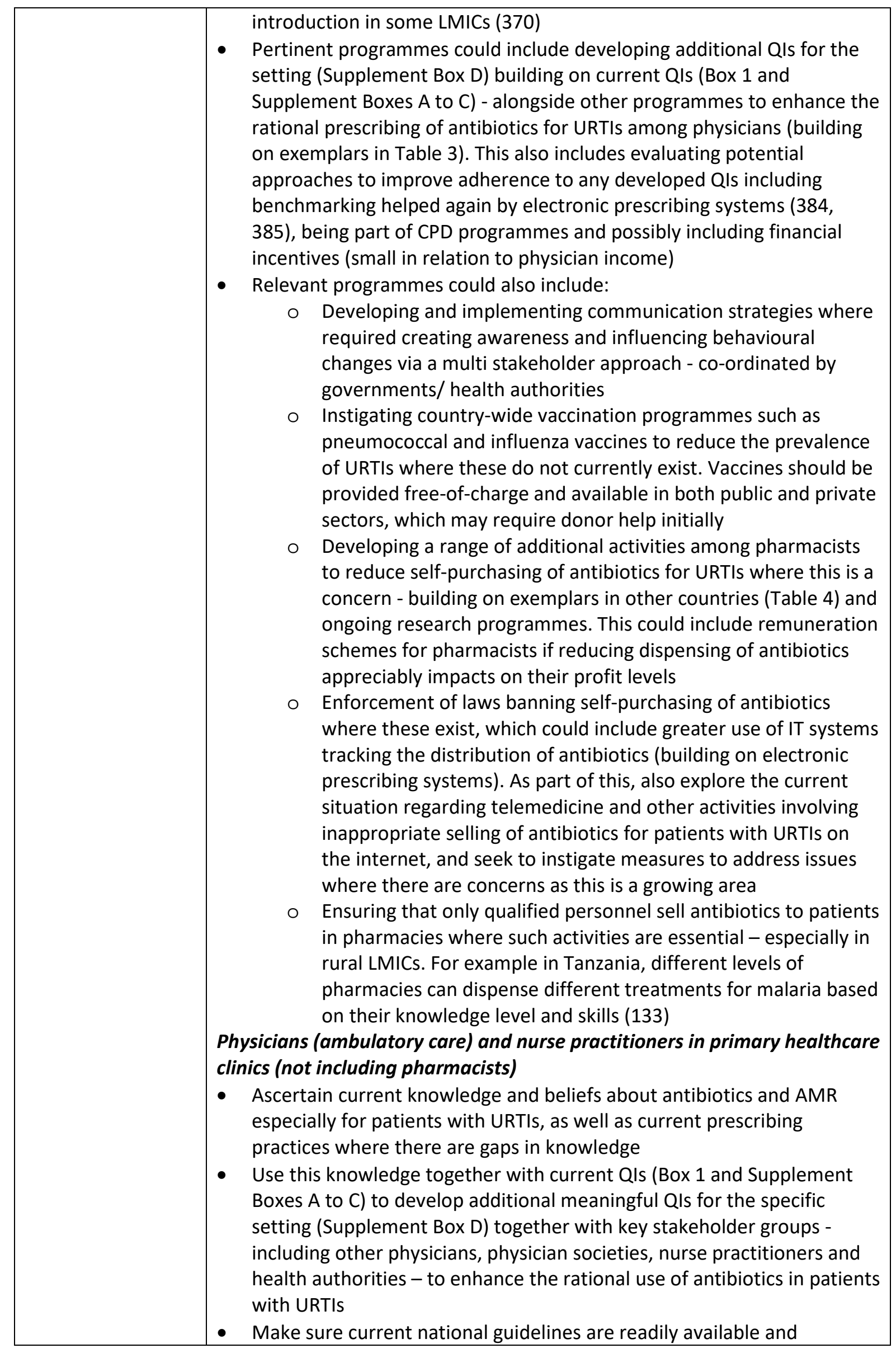




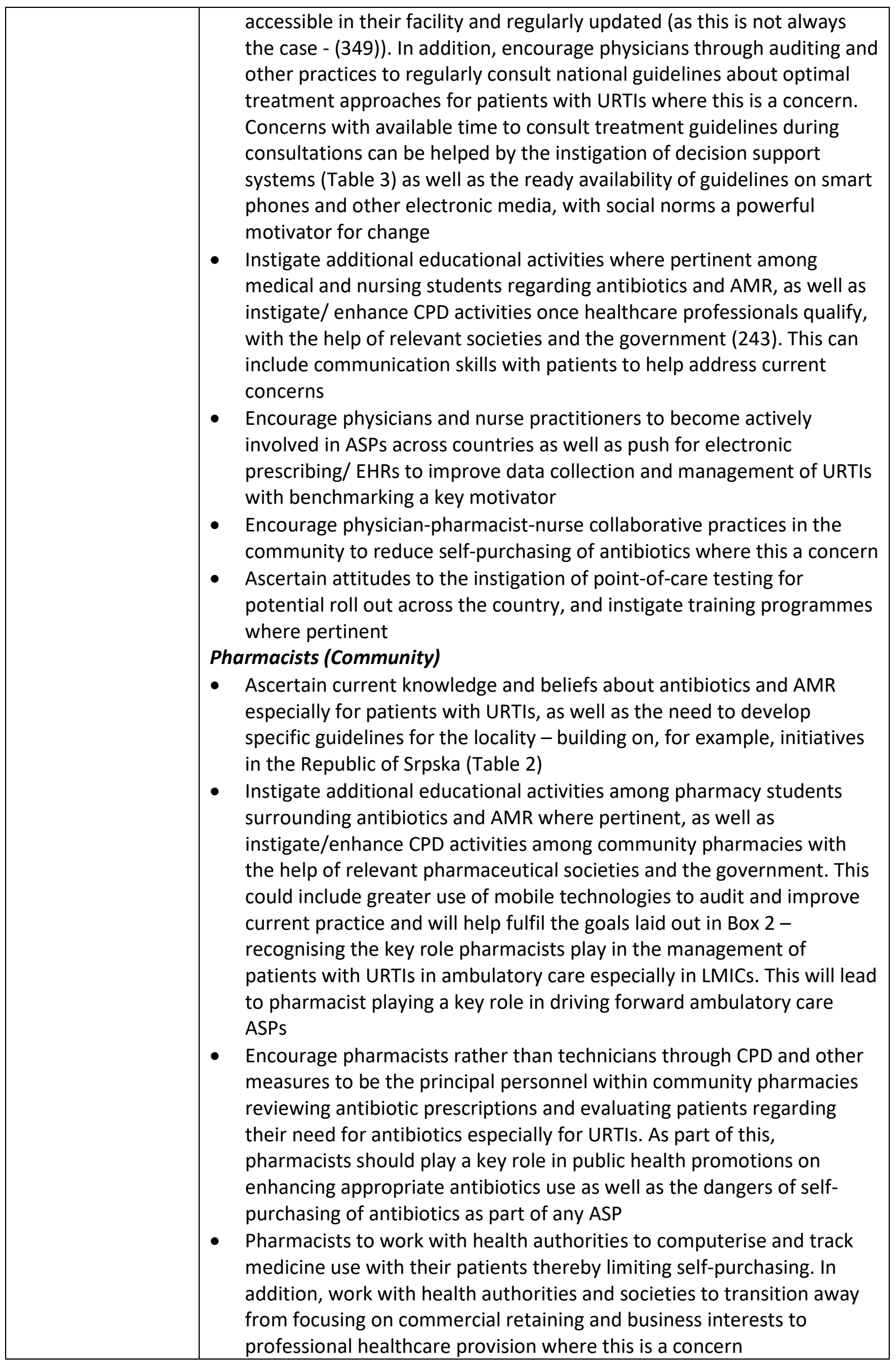




\begin{tabular}{|c|c|}
\hline & $\begin{array}{l}\text { - Advocate the introduction and benchmarking of national standards and } \\
\text { guidelines for Good Pharmacy Practice (GPP) in community pharmacy } \\
\text { settings as part of CPD (or upgrade these where such practices exist) to } \\
\text { address inappropriate prescribing and dispensing of antibiotics for } \\
\text { URTIs } \\
\text { Empower pharmacists to perform rapid diagnostic testing and } \\
\text { assessments where appropriate and cost-effective as evidence by } \\
\text { current high requests for antibiotics among patients with URTIs or their } \\
\text { children in a number of LMICs, and to help review current antibiotic use } \\
\text { among key stakeholder groups } \\
\text { Patients and the public } \\
\text { - Instigate health education programmes in schools if needed regarding } \\
\text { the appropriate use of antibiotics and AMR } \\
\text { Ascertain the rationale for any self-purchasing of antibiotics for URTIs if } \\
\text { needed. This is particularly important in LMICs where access, availability } \\
\text { and affordability to see a physician are problematic. In these situations, } \\
\text { legislation banning the self-purchasing of antibiotics may be counter- } \\
\text { productive. This is especially important in rural areas where pharmacists } \\
\text { may be the only healthcare professionals that patients see; } \\
\text { alternatively, they cannot afford to see both a physician and to } \\
\text { purchase pertinent medicines } \\
\text { Concurrent with this, increase advocacy for appropriate use of } \\
\text { antibiotics, and increase access to information regarding antibiotics and } \\
\text { AMR through advocacy programmes, patient information leaflets, social } \\
\text { media, and other community-based activities } \\
\text { In addition, monitor and educate households at high risk of URTIs (e.g. } \\
\text { those with young children) about antibiotics and AMR, again through } \\
\text { multiple media including the internet and mobile technologies } \\
\text { Use educational initiatives to encourage parents/caregivers of young } \\
\text { children to seek professional help for URTIs, including community } \\
\text { pharmacists as the most appropriate person initially (Section 3.4.3) }\end{array}$ \\
\hline $\begin{array}{l}\text { Longer term } \\
\text { potential strategies }\end{array}$ & $\begin{array}{l}\text { The findings from the situational analyses and ongoing educational activities } \\
\text { can be used together with other research findings within each LMIC to } \\
\text { develop pertinent strategies for all key stakeholder groups. Ongoing } \\
\text { strategies are likely to include: } \\
\text { - Health authorities/ Governments } \\
\text { O Regular monitoring of the prescribing and dispensing of } \\
\text { antibiotics for patients with URTIs as part of agreed NAPs, } \\
\text { including creating databases. This includes instigating electronic } \\
\text { prescribing and tracking systems and addressing issues with } \\
\text { telemedicine where concerns are raised } \\
\text { o Instigation of additional multiple strategies where pertinent to } \\
\text { improve antibiotic utilisation for URTIs - including potential } \\
\text { point-of-care testing, clinical decision support systems, regular } \\
\text { updating of guidelines including those for infection prevention } \\
\text { and control as well as academic detailing } \\
\text { O Regularly review ongoing vaccination programmes and update } \\
\text { if necessary - this may mean the need for additional donor help } \\
\text { o Increasing investment in research for new and existing } \\
\text { antimicrobials, diagnostic tools, alternative medicines and } \\
\text { vaccines }\end{array}$ \\
\hline
\end{tabular}




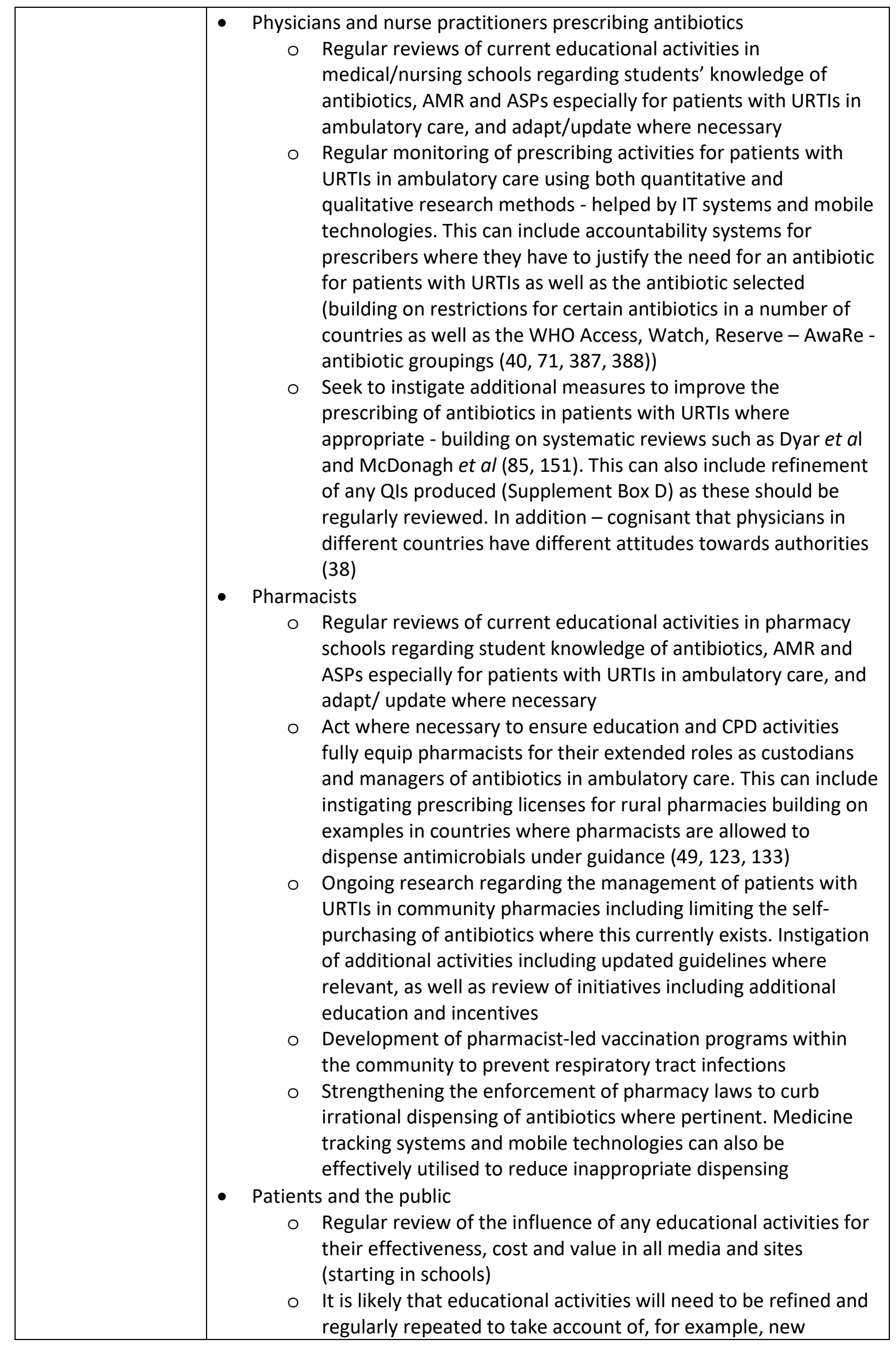




\begin{tabular}{|l|l|}
\hline & $\begin{array}{l}\text { mothers who have not been exposed to previous initiatives/not } \\
\text { aware of these and new elderly patients become more } \\
\text { susceptible to URTIs }\end{array}$ \\
\hline
\end{tabular}

NB: $A M R=$ antimicrobial resistance, $A S P s=$ antimicrobial stewardship programmes, $\mathrm{CPD}-$ continuous professional development, EHRs: Electronic Health Records, NAP = national action plan, QIs = quality indicators; URTIs = upper respiratory tract infections

Supplement Box D contains key activities that must be borne in mind when developing and testing new QIs for specific situations in ambulatory care among LMICs, building on previous examples (Box 1 and Supplement Boxes A to C).

These multiple activities among all key stakeholder groups should be combined as part of ASPs in ambulatory care to improve the future use of antibiotics, and build on ongoing NAPs. Further research though is needed in LMICs to measure the impact of such initiatives especially around reducing the self-purchasing of antbiotics; tracking antibiotics through the supply chain; enforcing legislation where pertinent and developing cost-effective health educational initiatives among patients and parents of children. We will be monitoring and reporting on such activities in the future.

We are aware of a number of limitations with this research including the fact that we did not undertake a systematic review. However, the reasons for this are discussed. We have though contextualised the findings of numerous publications to provide direction of possible short, medium and long term strategies to enhance the appropriate use of antibiotics in patients with URTIs especially in LMIC. We believe these recommendations are robust based on the experience and knowledge of the multiple co-authors across LMICs, and should provide future guidance.

Funding: This review manuscript receives no financial support.

Acknowledgments: The authors are much grateful to the Library of UPNM for their support to provide pertinent manuscripts.

Conflicts of Interest: The authors possess no conflict of interest. However, a number of the authors are employed by governments or health insurance agencies or are advisers to them.

\section{ORCID Numbers}

Brian Godman: http://orcid.org/0000-0001-6539-6972

Judy McKimm: 0000-0002-8949-5067

Israel Sefah: http://orcid.org/0000-0001-6963-0519

Amanj Kurdi: http://orcid.org/0000-0001-5036-1988

Arianit Jakupi: 0000-0002-7719-9690

Zikria Saleem: https://orcid.org/0000-0003-3202-6347

Dan Kibuule: http://orcid.org/0000-0002-6908-2177

Joseph Fadare: http://orcid.org/0000-0002-5641-1402

Vanda Marković-Peković: https://orcid.org/0000-0001-8963-5720

Aubrey Chichonyi Kalungia: http://orcid.org/0000-0003-2554-1236

Natalie Schellack: https://orcid.org/0000-0001-9690-6285

Johanna C Meyer: http://orcid.org/0000-0003-0462-5713

Thuy Nguyen Thi Phuong: https://orcid.org/0000-0001-7939-5276

\section{REFERENCES}

1. Founou RC, Founou LL, Essack SY. Clinical and economic impact of antibiotic resistance in developing countries: A systematic review and meta-analysis. PloS one. 2017;12(12):e0189621. 
2. Taylor J HM, Yerushalmi E, Smith R, Bellasio J, Vardavas R, et al. Estimating the economic costs of antimicrobial resistance: model and results. 2014. Available at URL: http://www.rand.org/content/dam/rand/pubs/research_reports/RR900/RR911/RAND_RR911.pdf. 3. O'Neill J. Securing new drugs for future generations: the pipeline of antibiotics. The review of antimicrobial resistance. Available at URL: https://amrreview.org/sites/default/files/SECURING\%20NEW\%20DRUGS\%20FOR\%2OFUTURE\%20GENERATIONS \%20FINAL\%20WEB_0.pdf

4. Laxminarayan R, Duse A, Wattal C, Zaidi AK, Wertheim HF, Sumpradit N, et al. Antibiotic resistance-the need for global solutions. The Lancet Infectious diseases. 2013;13(12):1057-98.

5. World Bank Group - DRUG-RESISTANT INFECTIONS - A Threat to Our Economic Future. Available at URL: http://documents.worldbank.org/curated/en/323311493396993758/pdf/114679REVISED-v2-Drug-Resistant-Infections-Final-Report.pdf.

6. Shallcross $\mathrm{L}$, Howard SJ, Fowler T, Davies SC. Tackling the threat of antimicrobial resistance: from policy to sustainable action. Philosophical Transactions of the Royal Society B: Biological Sciences. 2015;370(1670):20140082.

7. Michael CA, Dominey-Howes D, Labbate M. The antimicrobial resistance crisis: causes, consequences, and management. Front Public Health. 2014;2:145.

8. Centers for Disease Prevention and Control. ANTIBIOTIC RESISTANCE THREATS in the United States, 2013. Available at URL: https://www.cdc.gov/drugresistance/pdf/ar-threats-2013-508.pdf.

9. Fair RJ, Tor Y. Antibiotics and bacterial resistance in the 21st century. Perspectives in medicinal chemistry. 2014;6:25-64.

10. World Health Organisation. Antimicrobial resistance. 2018. Available at URL: http://www.who.int/news-room/fact-sheets/detail/antimicrobial-resistance.

11. Antonanzas $\mathrm{F}$, Goossens $\mathrm{H}$. The economics of antibiotic resistance: a claim for personalised treatments. Eur J Health Econ. 2019;20(4):483-485 12. Klein EY, Van Boeckel TP, Martinez EM, Pant $S$, Gandra S, Levin SA, et al. Global increase and geographic convergence in antibiotic consumption between 2000 and 2015. Proceedings of the National Academy of Sciences of the United States of America. 2018;115(15):E3463-e70.

13. Reardon S. Antibiotic resistance sweeping developing world. Nature. 2014;509(7499):141-2.

14. Aslam B, Wang W, Arshad MI, Khurshid M, Muzammil S, Rasool MH, et al. Antibiotic resistance: a rundown of a global crisis. Infection and drug resistance. 2018;11:1645-58.

15. Hofer U. The cost of antimicrobial resistance. Nature reviews Microbiology. 2019;17(1):3.

16. Cassini A, Hogberg LD, Plachouras D, Quattrocchi A, Hoxha A, Simonsen GS, et al.

Attributable deaths and disability-adjusted life-years caused by infections with antibiotic-resistant bacteria in the EU and the European Economic Area in 2015: a population-level modelling analysis. The Lancet Infectious diseases. 2019;19(1):56-66.

17. Llor C, Bjerrum L. Antimicrobial resistance: risk associated with antibiotic overuse and initiatives to reduce the problem. Therapeutic advances in drug safety. 2014;5(6):229-41.

18. Prestinaci F, Pezzotti P, Pantosti A. Antimicrobial resistance: a global multifaceted phenomenon. Pathogens and global health. 2015;109(7):309-18.

19. Laxminarayan R, Sridhar D, Blaser M, Wang M, Woolhouse M. Achieving global targets for antimicrobial resistance. Science. 2016;353(6302):874-5.

20. Aly SM. Risk of antimicrobial misuse. International journal of health sciences. 2013;7(1):V-vii. 21. Shaikhan F, Rawaf S, Majeed A, Hassounah S. Knowledge, attitude, perception and practice regarding antimicrobial use in upper respiratory tract infections in Qatar: a systematic review. JRSM open. 2018;9(9):2054270418774971.

22. Goossens H. Antibiotic consumption and link to resistance. Clinical microbiology and infection. 2009;15 Suppl 3:12-5.

23. Bell BG, Schellevis F, Stobberingh E, Goossens H, Pringle M. A systematic review and metaanalysis of the effects of antibiotic consumption on antibiotic resistance. BMC Infectious Diseases. 2014;14:13-. 
24. Goossens H, Ferech M, Vander Stichele R, Elseviers M. Outpatient antibiotic use in Europe and association with resistance: a cross-national database study. Lancet. 2005;365(9459):579-87. 25. Tyrstrup M, Melander E, Hedin K, Beckman A, Molstad S. Children with respiratory tract infections in Swedish primary care; prevalence of antibiotic resistance in common respiratory tract pathogens and relation to antibiotic consumption. BMC Infect Dis. 2017;17(1):603.

26. Nasrin D, Collignon PJ, Roberts L, Wilson EJ, Pilotto LS, Douglas RM. Effect of beta lactam antibiotic use in children on pneumococcal resistance to penicillin: prospective cohort study. BMJ. 2002;324(7328):28-30.

27. Leekha S, Terrell CL, Edson RS. General Principles of Antimicrobial Therapy. Mayo Clinic proceedings. 2011;86(2):156-67.

28. Costelloe C, Metcalfe C, Lovering A, Mant D, Hay AD. Effect of antibiotic prescribing in primary care on antimicrobial resistance in individual patients: systematic review and meta-analysis. BMJ. 2010;340:c2096.

29. Wilkinson A, Ebata A, MacGregor H. Interventions to Reduce Antibiotic Prescribing in LMICs: A Scoping Review of Evidence from Human and Animal Health Systems. Antibiotics. 2018;8(1).

30. Marston HD, Dixon DM, Knisely JM, Palmore TN, Fauci AS. Antimicrobial Resistance. Jama. 2016;316(11):1193-204.

31. Alvarez-Uria G, Gandra S, Mandal S, Laxminarayan R. Global forecast of antimicrobial resistance in invasive isolates of Escherichia coli and Klebsiella pneumoniae. International journal of infectious diseases. 2018;68:50-3.

32. WHO. Antimicrobial resistance. Fact Sheet. 2018. Available at URL: http://www.who.int/mediacentre/factsheets/fs194/en/.

33. Nordmann P, Naas T, Poirel L. Global spread of Carbapenemase-producing Enterobacteriaceae. Emerging infectious diseases. 2011;17(10):1791-8.

34. Fernandes MR, Moura Q, Sartori L, Silva KC, Cunha MP, Esposito F, et al. Silent dissemination of colistin-resistant Escherichia coli in South America could contribute to the global spread of the mcr-1 gene. Euro surveillance. 2016;21(17).

35. Scully C, Robinson AN, Wiesenfeld D. Antimicrobial resistance: Dangerous abuse. British dental journal. 2016;220(4):154-5.

36. Mendelson M, Brink A, Gouws J, Mbelle N, Naidoo V, Pople T, et al. The One Health stewardship of colistin as an antibiotic of last resort for human health in South Africa. The Lancet Infectious diseases. 2018;18(9):e288-e94.

37. Levy SB, Marshall B. Antibacterial resistance worldwide: causes, challenges and responses. Nature medicine. 2004;10(12 Suppl):S122-9.

38. Wojkowska-Mach J, Godman B, Glassman A, Kurdi A, Pilc A, Rozanska A, et al. Antibiotic consumption and antimicrobial resistance in Poland; findings and implications. Antimicrobial Resistance \& Infection Control. 2018;7(1):136.

39. Labuschagne Q SN, Gous A, Bronkhorst E, Schellack G, van Tonder L et al. COLISTIN: adult and paediatric guideline for South Africa, 2016. Southern African Journal of Infectious Diseases 2016;31(1):3-7.

40. Furst J, Cizman M, Mrak J, Kos D, Campbell S, Coenen S, et al. The influence of a sustained multifaceted approach to improve antibiotic prescribing in Slovenia during the past decade: findings and implications. Expert review of anti-infective therapy. 2015;13(2):279-89.

41. Roope LSJ, Smith RD, Pouwels KB, Buchanan J, Abel L, Eibich P, et al. The challenge of antimicrobial resistance: What economics can contribute. Science. 2019;364(6435).

42. Padget $M$, Guillemot $D$, Delarocque-Astagneau $E$. Measuring antibiotic consumption in lowincome countries: a systematic review and integrative approach. International journal of antimicrobial agents. 2016;48(1):27-32.

43. Auta A, Hadi MA, Oga E, Adewuyi EO, Abdu-Aguye SN, Adeloye D, et al. Global access to antibiotics without prescription in community pharmacies: a systematic review and meta-analysis. J Infect. 2019;78(1):8-18 
44. Ramani VK, Pattankar J, Puttahonnappa SK. Acute Respiratory Infections among Under-Five Age Group Children at Urban Slums of Gulbarga City: A Longitudinal Study. Journal of Clinical and Diagnostic Research. 2016;10(5):LC08-LC13.

45. Le Doare K, Barker Cl, Irwin A, Sharland M. Improving antibiotic prescribing for children in the resource-poor setting. British journal of clinical pharmacology. 2015;79(3):446-55.

46. Nga DTT, Chuc NTK, Hoa NP, Hoa NQ, Nguyen NTT, Loan HT, et al. Antibiotic sales in rural and urban pharmacies in northern Vietnam: an observational study. BMC Pharmacology \& Toxicology. 2014;15:6-.

47. Ayukekbong JA, Ntemgwa M, Atabe AN. The threat of antimicrobial resistance in developing countries: causes and control strategies. Antimicrobial Resistance \& Infection Control. 2017;6(1):47.

48. Faizullah M, Nisar-Ur-Rahman, Umar M, Anwar M, Sarfraz M. A cross-sectional study on knowledge, attitude and practices of medical doctors towards antibiotic prescribing patterns and resistance in Khyber Pakhtun Khawah, Pakistan ARTICLE INFO ABSTRACT2017. 38-46 p.

49. Sakeena MHF, Bennett AA, McLachlan AJ. Non-prescription sales of antimicrobial agents at community pharmacies in developing countries: a systematic review. International journal of antimicrobial agents. 2018;52(6):771-82.

50. Farley E, Stewart A, Davies MA, Govind M, Van den Bergh D, Boyles TH. Antibiotic use and resistance: Knowledge, attitudes and perceptions among primary care prescribers in South Africa. South African medical journal. 2018;108(9):763-71.

51. Nguyen QH, Nguyen TK, Ho D, Larsson M, Eriksson B, Lundborg CS. Unnecessary antibiotic use for mild acute respiratory infections during 28-day follow-up of 823 children under five in rural Vietnam. Trans R Soc Trop Med Hyg. 2011;105(11):628-36.

52. Chang J, Xu S, Zhu S, Li Z, Yu J, Zhang Y, et al. Assessment of non-prescription antibiotic dispensing at community pharmacies in China with simulated clients: a mixed cross-sectional and longitudinal study. The Lancet Infectious diseases. 2019.

53. Dye C. After 2015: infectious diseases in a new era of health and development. Philosophical transactions of the Royal Society of London Series B, Biological sciences. 2014;369(1645):20130426. 54. Walson JL, Berkley JA. The impact of malnutrition on childhood infections. Current opinion in infectious diseases. 2018;31(3):231-6.

55. Checkley W, Pollard SL, Siddharthan T, Babu GR, Thakur M, Miele CH, et al. Managing threats to respiratory health in urban slums. The Lancet Respiratory medicine. 2016;4(11):852-4.

56. Godman B, Fadare J, Kibuule D, Irawati L, Mubita M, Ogunleye O, et al. Initiatives Across Countries to Reduce Antibiotic Utilisation and Resistance Patterns: Impact and Implications. In: Arora G, Sajid A, Kalia VC, editors. Drug Resistance in Bacteria, Fungi, Malaria, and Cancer. Cham: Springer International Publishing; 2017. p. 539-76.

57. Md Rezal RS, Hassali MA, Alrasheedy AA, Saleem F, Md Yusof FA, Godman B. Physicians' knowledge, perceptions and behaviour towards antibiotic prescribing: a systematic review of the literature. Expert review of anti-infective therapy. 2015;13(5):665-80.

58. Schwartländer B. World health Organization. Antibiotics changed modern medicine, but we must act to protect them. 2015. Available at URL: http://www.wpro.who.int/china/mediacentre/releases/2015/20151119/en/.

59. Atif M, Asghar S, Mushtaq I, Malik I, Amin A, Babar Z, Scahill S. What drives inappropriate use of antibiotics? A mixed methods study from Bahawalpur, Pakistan. Infection and Drug Resistance 2019:12 687-699.

60. Huttner B, Goossens H, Verheij T, Harbarth S. Characteristics and outcomes of public campaigns aimed at improving the use of antibiotics in outpatients in high-income countries. The Lancet Infectious diseases. 2010;10(1):17-31.

61. Dar OA, Hasan R, Schlundt J, Harbarth S, Caleo G, Dar FK, et al. Exploring the evidence base for national and regional policy interventions to combat resistance. Lancet. 2016;387(10015):285-95. 
62. Bao L, Peng R, Wang $Y$, Ma R, Ren X, Meng W, et al. Significant reduction of antibiotic consumption and patients' costs after an action plan in China, 2010-2014. PloS one.

2015;10(3):e0118868.

63. WHO. ANTIMICROBIAL RESISTANCE. Global Report on Surveillance, Available at URL: http://www.euro.who.int/en/health-topics/disease-prevention/antimicrobialresistance/news/news/2014/04/new-report-antibiotic-resistance-a-global-health-threat 64. Jinks T, Lee N, Sharland M, Rex J, Gertler N, Diver M, et al. A time for action: antimicrobial resistance needs global response. Bull World Health Organ. 2016;94(8):558-a.

65. European Commission. A European One Health Action Plan against Antimicrobial Resistance (AMR). 2017. Available at URL:

https://ec.europa.eu/health/amr/sites/amr/files/amr_action_plan_2017_en.pdf.

66. Seale AC, Gordon NC, Islam J, Peacock SJ, Scott JAG. AMR Surveillance in low and middleincome settings - A roadmap for participation in the Global Antimicrobial Surveillance System (GLASS). Wellcome open research. 2017;2:92.

67. CDC. Antibiotic Prescribing and Use in Doctor's Offices. For Healthcare Professionals. 2018. Available at URL: https://www.cdc.gov/antibiotic-use/community/for-hcp/index.html.

68. Schellack N, Benjamin D, Brink A, Duse A, Faure K, Goff D, et al. A situational analysis of current antimicrobial governance, regulation, and utilization in South Africa. International journal of infectious diseases. 2017;64:100-6.

69. Rezal RS, Hassali MA, Alrasheedy AA, Saleem F, Yusof FA, Kamal M, et al. Prescribing patterns for upper respiratory tract infections: a prescription-review of primary care practice in Kedah, Malaysia, and the implications. Expert review of anti-infective therapy. 2015;13(12):1547-56. 70. Abilova V, Kurdi A, Godman B. Ongoing initiatives in Azerbaijan to improve the use of antibiotics; findings and implications. Expert review of anti-infective therapy. 2018;16(1):77-84.

71. Bojanic L, Markovic-Pekovic V, Skrbic R, Stojakovic N, Ethermanovic M, Bojanic J, et al. Recent Initiatives in the Republic of Srpska to Enhance Appropriate Use of Antibiotics in Ambulatory Care; Their Influence and Implications. Frontiers in pharmacology. 2018;9:442.

72. Raka L, Kurti A, Jakupi A, Krasniqi S, Turjaka A. Kosovo's national action plan for antimicrobial resistance. The Lancet Infectious diseases. 2019;19(3):244.

73. Newitt S, Oloyede O, Puleston R, Hopkins S, Ashiru-Oredope D. Demographic, Knowledge and Impact Analysis of 57,627 Antibiotic Guardians Who Have Pledged to Contribute to Tackling Antimicrobial Resistance. Antibiotics. 2019;8(1).

74. Jacobs TG, Robertson J, van den Ham HA, Iwamoto K, Bak Pedersen H, Mantel-Teeuwisse AK. Assessing the impact of law enforcement to reduce over-the-counter (OTC) sales of antibiotics in low- and middle-income countries; a systematic literature review. BMC health services research. 2019;19(1):536.

75. Petersen I, Hayward AC. Antibacterial prescribing in primary care. The Journal of antimicrobial chemotherapy. 2007;60 Suppl 1:i43-7.

76. Little P, Stuart B, Francis N, Douglas E, Tonkin-Crine S, Anthierens S, et al. Effects of internetbased training on antibiotic prescribing rates for acute respiratory-tract infections: a multinational, cluster, randomised, factorial, controlled trial. Lancet. 2013;382(9899):1175-82.

77. Francis NA, Butler CC, Hood K, Simpson S, Wood F, Nuttall J. Effect of using an interactive booklet about childhood respiratory tract infections in primary care consultations on reconsulting and antibiotic prescribing: a cluster randomised controlled trial. The BMJ. 2009;339:b2885.

78. Cosby JL, Francis N, Butler CC. The role of evidence in the decline of antibiotic use for common respiratory infections in primary care. The Lancet Infectious diseases. 2007;7(11):749-56.

79. Tyrstrup M, Beckman A, Molstad S, Engstrom S, Lannering C, Melander E, et al. Reduction in antibiotic prescribing for respiratory tract infections in Swedish primary care- a retrospective study of electronic patient records. BMC Infect Dis. 2016;16(1):709.

80. Lee ML, Cho CY, Hsu CL, Chen CJ, Chang LY, Lee YS, et al. Recent trends in antibiotic prescriptions for acute respiratory tract infections in pediatric ambulatory care in Taiwan, 2000- 
2009: A nationwide population-based study. Journal of microbiology, immunology, and infection. 2016;49(4):554-60.

81. Steinman MA, Gonzales R, Linder JA, Landefeld CS. Changing use of antibiotics in community-based outpatient practice, 1991-1999. Annals of internal medicine. 2003;138(7):525-33. 82. Grijalva CG, Nuorti JP, Griffin MR. Antibiotic prescription rates for acute respiratory tract infections in US ambulatory settings. Jama. 2009;302(7):758-66.

83. Havers FP, Hicks LA, Chung JR, Gaglani M, Murthy K, Zimmerman RK, et al. Outpatient Antibiotic Prescribing for Acute Respiratory Infections During Influenza Seasons. JAMA Netw Open. 2018;1(2):e180243.

84. Dasaraju PV, Liu C. Infections of the Respiratory System. In: th, Baron S, editors. Medical Microbiology. Galveston (TX): University of Texas Medical Branch at Galveston. The University of Texas Medical Branch at Galveston.; 1996.

85. Dyar OJ, Beovic B, Vlahovic-Palcevski V, Verheij T, Pulcini C. How can we improve antibiotic prescribing in primary care? Expert review of anti-infective therapy. 2016;14(4):403-13.

86. van der Meer JWM. The infectious disease challenges of our time. Frontiers in Public Health. 2013;1:7.

87. Vaz LE, Kleinman KP, Raebel MA, Nordin JD, Lakoma MD, Dutta-Linn MM, et al. Recent trends in outpatient antibiotic use in children. Pediatrics. 2014;133(3):375-85.

88. Wei X, Zhang Z, Hicks JP, Walley JD, King R, Newell JN, et al. Long-term outcomes of an educational intervention to reduce antibiotic prescribing for childhood upper respiratory tract infections in rural China: Follow-up of a cluster-randomised controlled trial. PLoS Med. 2019;16(2):e1002733.

89. Barnett ML, Linder JA. Antibiotic prescribing for adults with acute bronchitis in the United States, 1996-2010. Jama. 2014;311(19):2020-2.

90. Fleming-Dutra KE, Hersh AL, Shapiro DJ, Bartoces M, Enns EA, File TM. Prevalence of inappropriate antibiotic prescriptions among US ambulatory care visits, 2010-2011. Jama. 2016;315.

91. Kalungia AC, Burger J, Godman B, Costa JO, Simuwelu C. Non-prescription sale and dispensing of antibiotics in community pharmacies in Zambia. Expert review of anti-infective therapy. 2016;14(12):1215-23.

92. Kibuule D, Kagoya HR, Godman B. Antibiotic use in acute respiratory infections in under-fives in Uganda: findings and implications. Expert review of anti-infective therapy. 2016;14(9):863-72.

93. Ebell $\mathrm{MH}$, Radke T. Antibiotic use for viral acute respiratory tract infections remains common. The American journal of managed care. 2015;21(10):e567-75.

94. Simasek M, Blandino DA. Treatment of the common cold. American family physician. 2007;75(4):515-20.

95. Butler CC, Hood K, Verheij T, Little P, Melbye H, Nuttall J, et al. Variation in antibiotic prescribing and its impact on recovery in patients with acute cough in primary care: prospective study in 13 countries. BMJ. 2009;338:b2242-b.

96. Lee TH, Wong JG, Lye DC, Chen MI, Loh VW, Leo YS, et al. Medical and psychosocial factors associated with antibiotic prescribing in primary care: survey questionnaire and factor analysis. The British journal of general practice. 2017;67(656):e168-e77.

97. Holloway KA, Ivanovska V, Wagner AK, Vialle-Valentin C, Ross-Degnan D. Prescribing for acute childhood infections in developing and transitional countries, 1990-2009. Paediatrics and international child health. 2015;35(1):5-13.

98. Hassali MA, Kamil TK, Md Yusof FA, Alrasheedy AA, Yusoff ZM, Saleem F, et al. General practitioners' knowledge, attitude and prescribing of antibiotics for upper respiratory tract infections in Selangor, Malaysia: findings and implications. Expert review of anti-infective therapy. 2015;13(4):511-20.

99. Spellberg B, Gilbert DN. The future of antibiotics and resistance: a tribute to a career of leadership by John Bartlett. Clinical infectious diseases : an official publication of the Infectious Diseases Society of America. 2014;59 Suppl 2:S71-5. 
100. Batura N, Cuevas C, Khan M, Wiseman V. How effective and cost-effective are behaviour change interventions in improving the prescription and use of antibiotics in low-income and middleincome countries? A protocol for a systematic review. BMJ open. 2018;8(5):e021517.

101. Thornton HV, Hay AD, Redmond NM, Turnbull SL, Christensen H, Peters TJ, et al. Throat swabs in children with respiratory tract infection: associations with clinical presentation and potential targets for point-of-care testing. Fam Pract. 2017;34(4):407-15.

102. Collignon P, Athukorala PC, Senanayake S, Khan F. Antimicrobial resistance: the major contribution of poor governance and corruption to this growing problem. PloS one. 2015;10(3):e0116746.

103. Alhomoud F, Aljamea Z, Almahasnah R, Alkhalifah K, Basalelah L, Alhomoud FK. Selfmedication and self-prescription with antibiotics in the Middle East-do they really happen? A systematic review of the prevalence, possible reasons, and outcomes. International journal of infectious diseases. 2017;57:3-12.

104. Rather IA, Kim BC, Bajpai VK, Park YH. Self-medication and antibiotic resistance: Crisis, current challenges, and prevention. Saudi journal of biological sciences. 2017;24(4):808-12.

105. Hersh AL, Shapiro DJ, Pavia AT, Shah SS. Antibiotic prescribing in ambulatory pediatrics in the United States. Pediatrics. 2011;128(6):1053-61.

106. Vazquez-Lago JM, Lopez-Vazquez P, Lopez-Duran A, Taracido-Trunk M, Figueiras A. Attitudes of primary care physicians to the prescribing of antibiotics and antimicrobial resistance: a qualitative study from Spain. Fam Pract. 2012;29(3):352-60.

107. Aly M, Balkhy HH. The prevalence of antimicrobial resistance in clinical isolates from Gulf Corporation Council countries. Antimicrob Resist Infect Control. 2012;1(1):26.

108. Teixeira Rodrigues A, Roque F, Falcao A, Figueiras A, Herdeiro MT. Understanding physician antibiotic prescribing behaviour: a systematic review of qualitative studies. International journal of antimicrobial agents. 2013;41(3):203-12.

109. Torres NF, Chibi B, Middleton LE, Solomon VP, Mashamba-Thompson TP. Evidence of factors influencing self-medication with antibiotics in low and middle-income countries: a systematic scoping review. Public health. 2019;168:92-101.

110. Murray CJ, Ortblad KF, Guinovart C, Lim SS, Wolock TM, Roberts DA, et al. Global, regional, and national incidence and mortality for HIV, tuberculosis, and malaria during 1990-2013: a systematic analysis for the Global Burden of Disease Study 2013. Lancet. 2014;384(9947):1005-70. 111. Kibuule D, Verbeeck RK, Nunurai R, Mavhunga F, Ene E, Godman B, et al. Predictors of tuberculosis treatment success under the DOTS program in Namibia. Expert review of respiratory medicine. 2018;12(11):979-87.

112. Davis JL, Fei M, Huang L. Respiratory infection complicating HIV infection. Current opinion in infectious diseases. 2008;21(2):184-90.

113. Satyanarayana S, Kwan A, Daniels B, Subbaraman R, McDowell A, Bergkvist S, et al. Use of standardised patients to assess antibiotic dispensing for tuberculosis by pharmacies in urban India: a cross-sectional study. The Lancet Infectious diseases. 2016;16(11):1261-8.

114. Miller R, Goodman C. Do chain pharmacies perform better than independent pharmacies? Evidence from a standardised patient study of the management of childhood diarrhoea and suspected tuberculosis in urban India. BMJ global health. 2017;2(3):e000457.

115. Nyazema N, Viberg N, Khoza S, Vyas S, Kumaranayake L, Tomson G, et al. Low sale of antibiotics without prescription: a cross-sectional study in Zimbabwean private pharmacies. The Journal of antimicrobial chemotherapy. 2007;59(4):718-26.

116. Erku DA, Mekuria AB, Belachew SA. Inappropriate use of antibiotics among communities of Gondar town, Ethiopia: a threat to the development of antimicrobial resistance. Antimicrobial Resistance \& Infection Control. 2017;6(1):112.

117. Haeseker MB, Dukers-Muijrers NHTM, Hoebe CJPA, Bruggeman CA, Cals JWL, Verbon A. Trends in antibiotic prescribing in adults in Dutch general practice. PloS one. 2012;7(12):e51860-e. 
118. Gasson J, Blockman M, Willems B. Antibiotic prescribing practice and adherence to guidelines in primary care in the Cape Town Metro District, South Africa. South African medical journal. 2018;108(4):304-10.

119. Holloway KA, Rosella L, Henry D. The Impact of WHO Essential Medicines Policies on Inappropriate Use of Antibiotics. PloS one. 2016;11(3):e0152020.

120. Ocan M, Obuku EA, Bwanga F, Akena D, Richard S, Ogwal-Okeng J, et al. Household antimicrobial self-medication: a systematic review and meta-analysis of the burden, risk factors and outcomes in developing countries. BMC public health. 2015;15:742.

121. Morgan DJ, Okeke IN, Laxminarayan R, Perencevich EN, Weisenberg S. Non-prescription antimicrobial use worldwide: a systematic review. The Lancet Infectious diseases. 2011;11(9):692701.

122. Torrone EA, Morrison CS, Chen P-L, Kwok C, Francis SC, Hayes RJ, et al. Prevalence of sexually transmitted infections and bacterial vaginosis among women in sub-Saharan Africa: An individual participant data meta-analysis of 18 HIV prevention studies. PLoS medicine. 2018;15(2):e1002511-e. 123. Nepal G, Bhatta S. Self-medication with Antibiotics in WHO Southeast Asian Region: A Systematic Review. Cureus. 2018;10(4):e2428.

124. Nakajima R, Takano T, Urnaa V, Khaliun N, Nakamura K. Antimicrobial use in a country with insufficient enforcement of pharmaceutical regulations: A survey of consumption and retail sales in Ulaanbaatar, Mongolia. Southern med review. 2010;3(1):19-23.

125. Laxminarayan R, Matsoso P, Pant S, Brower C, Rottingen JA, Klugman K, et al. Access to effective antimicrobials: a worldwide challenge. Lancet. 2016;387(10014):168-75.

126. Laxminarayan R, Chaudhury RR. Antibiotic Resistance in India: Drivers and Opportunities for Action. PLoS Med. 2016;13(3):e1001974.

127. Van Boeckel TP, Gandra S, Ashok A, Caudron Q, Grenfell BT, Levin SA, et al. Global antibiotic consumption 2000 to 2010: an analysis of national pharmaceutical sales data. The Lancet Infectious diseases. 2014;14(8):742-50.

128. Miller R, Goodman C. Performance of retail pharmacies in low- and middle-income Asian settings: a systematic review. Health Policy and Planning. 2016;31(7):940-53.

129. Haak H. Pharmaceuticals in two Brazilian villages: lay practices and perceptions. Soc Sci Med. 1988;27(12):1415-27.

130. Saradamma RD, Higginbotham N, Nichter M. Social factors influencing the acquisition of antibiotics without prescription in Kerala State, south India. Soc Sci Med. 2000;50(6):891-903.

131. Seeberg J. Connecting pills and people: an ethnography of the pharmaceutical nexus in Odisha, India. Medical anthropology quarterly. 2012;26(2):182-200.

132. Jasim AL, Fadhil TA, Taher SS: Self-medication practice among Iraqi patients in Baghdad city. Am J Pharmacol Sci. 2014; 2:18-23.

133. Mwita S, Jande M, Marwa K, Hamasaki K, Katabalo D, Burger J , Godman B et al. Medicines dispensers' knowledge on the implementation of an artemisinin-based combination therapy policy for the treatment of uncomplicated malaria in Tanzania. Journal of Pharmaceutical Health Services Research 2017;8:227-33.

134. Akinyandenu O AA. Irrational use and non-prescription sale of antibiotics in Nigeria: A need for change Journal of Scientific and Innovative Research. 2014;3(2):251-7.

135. Abdulraheem IS AA, Fatiregun AA. Self-medication with Antibiotics: Empirical Evidence from a Nigerian Rural Population BJPR. 2016;11(5):1-13.

136. Farah R, Lahoud N, Salameh P, Saleh N. Antibiotic dispensation by Lebanese pharmacists: a comparison of higher and lower socio-economic levels. Journal of infection and public health. 2015;8(1):37-46.

137. Barker AK, Brown K, Ahsan M, Sengupta S, Safdar N. Social determinants of antibiotic misuse: a qualitative study of community members in Haryana, India. BMC public health.

2017;17(1):333. 
138. Al-Faham Z, Habboub G, Takriti F. The sale of antibiotics without prescription in pharmacies in Damascus, Syria. Journal of infection in developing countries. 2011;5(5):396-9.

139. Mbonye AK, Buregyeya E, Rutebemberwa E, Clarke SE, Lal S, Hansen KS, et al. Prescription for antibiotics at drug shops and strategies to improve quality of care and patient safety: a crosssectional survey in the private sector in Uganda. BMJ open. 2016;6(3):e010632.

140. Apisarnthanarak A, Tunpornchai J, Tanawitt K, Mundy LM. Nonjudicious dispensing of antibiotics by drug stores in Pratumthani, Thailand. Infection control and hospital epidemiology. 2008;29(6):572-5.

141. Servia-Dopazo M, Figueiras A. Determinants of antibiotic dispensing without prescription: a systematic review. The Journal of antimicrobial chemotherapy. 2018;73(12):3244-53.

142. Kalungia A, Godman B. Implications of non-prescription antibiotic sales in China. The Lancet Infectious diseases. 2019.

143. Erku DA, Aberra SY. Non-prescribed sale of antibiotics for acute childhood diarrhea and upper respiratory tract infection in community pharmacies: a 2 phase mixed-methods study. Antimicrob Resist Infect Control. 2018;7:92.

144. Rudolf PM, Bernstein IB. Counterfeit drugs. N Engl J Med. 2004;350(14):1384-6.

145. Mendelson M, Rottingen JA, Gopinathan U, Hamer DH, Wertheim H, Basnyat B, et al. Maximising access to achieve appropriate human antimicrobial use in low-income and middleincome countries. Lancet. 2016;387(10014):188-98.

146. Pincock S. WHO tries to tackle problem of counterfeit medicines in Asia. BMJ (Clinical research ed). 2003;327(7424):1126.

147. Fadare JO, Adeoti AO, Desalu OO, Enwere OO, Makusidi AM, Ogunleye O, et al. The prescribing of generic medicines in Nigeria: knowledge, perceptions and attitudes of physicians. Expert review of pharmacoeconomics \& outcomes research. 2016;16(5):639-50.

148. Khan B, Godman B, Babar A, Hussain S, Mahmood S, Aqeel T. Assessment of active pharmaceutical ingredients in the registration procedures in Pakistan: implications for the future. GaBI Journal. 2016;5(4):156-63.

149. Acosta A, Vanegas EP, Rovira J, Godman B, Bochenek T. Medicines shortages: Gaps between countries and global perspectives. Front Pharmacol. 2019;10:763

150. Malan L, Labuschagne Q, Brechtelsbauer E, Goff DA, Schellack N. Sustainable Access to Antimicrobials; A Missing Component to Antimicrobial Stewardship-A Tale of Two Countries. Front Public Health. 2018;6:324.

151. McDonagh MS, Peterson K, Winthrop K, Cantor A, Lazur BH, Buckley DI. Interventions to reduce inappropriate prescribing of antibiotics for acute respiratory tract infections: summary and update of a systematic review. The Journal of international medical research. 2018;46(8):3337-57.

152. Köchling A, Löffler C, Reinsch S, Hornung A, Böhmer F, Altiner A, et al. Reduction of antibiotic prescriptions for acute respiratory tract infections in primary care: a systematic review.

Implementation Science. 2018;13(1):47.

153. McKay R, Mah A, Law MR, McGrail K, Patrick DM. Systematic Review of Factors Associated with Antibiotic Prescribing for Respiratory Tract Infections. Antimicrob Agents Chemother. 2016;60(7):4106-18.

154. Roque F, Herdeiro MT, Soares S, Teixeira Rodrigues A, Breitenfeld L, Figueiras A. Educational interventions to improve prescription and dispensing of antibiotics: a systematic review. BMC public health. 2014;14:1276-.

155. Lescure D, Paget J, Schellevis F, van Dijk L. Determinants of Self-Medication With Antibiotics in European and Anglo-Saxon Countries: A Systematic Review of the Literature. Front Public Health. 2018;6:370.

156. Zanichelli V, Tebano G, Gyssens IC, Vlahovic-Palcevski V, Monnier AA, Stanic Benic M, et al. Patient-related determinants of antibiotic use: a systematic review. Clinical microbiology and infection. 2019;25(1):48-53. 
157. Cross EL, Tolfree R, Kipping R. Systematic review of public-targeted communication interventions to improve antibiotic use. The Journal of antimicrobial chemotherapy. 2017;72(4):97587.

158. Global Respiratory Infection Partnership - GRIP. The Global Respiratory Infection Partnership Declaration. 2014. Available at URL: http://www.grip-initiative.org/about-thepartnership/partnerships-mission/the-grip-declaration.

159. Essack S, Bell J, Shephard A. Community pharmacists-Leaders for antibiotic stewardship in respiratory tract infection. Journal of clinical pharmacy and therapeutics. 2018;43(2):302-7.

160. WHO Collaborating Centre on Patient Safety. The University of Geneva Hospitals and Faculty of Medicine. Evaluation of antibiotic awareness campaigns. 2017. Available at URL:

https://www.who.int/selection_medicines/committees/expert/21/applications/s6_antibiotic_aware ness_campaigns.pdf.

161. Haque M, McKimm J, Godman B, Abu Bakar M, Sartelli M. Initiatives to reduce postoperative surgical site infections of the head and neck cancer surgery with a special emphasis on developing countries. Expert review of anticancer therapy. 2019;19(1):81-92.

162. Godman B, Wettermark B, van Woerkom M, Fraeyman J, Alvarez-Madrazo S, Berg C, et al. Multiple policies to enhance prescribing efficiency for established medicines in Europe with a particular focus on demand-side measures: findings and future implications. Frontiers in pharmacology. 2014;5:106.

163. Godman B, Malmstrom RE, Diogene E, Gray A, Jayathissa S, Timoney A, et al. Are new models needed to optimize the utilization of new medicines to sustain healthcare systems? Expert review of clinical pharmacology. 2015;8(1):77-94.

164. Godman B, Bucsics A, Vella Bonanno P, Oortwijn W, Rothe CC, Ferrario A, et al. Barriers for Access to New Medicines: Searching for the Balance Between Rising Costs and Limited Budgets. Front Public Health. 2018;6:328.

165. Godman B, Malmstrom RE, Diogene E, Jayathissa S, McTaggart S, Cars T, et al. Dabigatran - a continuing exemplar case history demonstrating the need for comprehensive models to optimize the utilization of new drugs. Frontiers in pharmacology. 2014;5:109.

166. Ermisch M, Bucsics A, Vella Bonanno P, Arickx F, Bybau A, Bochenek T, et al. Payers' Views of the Changes Arising through the Possible Adoption of Adaptive Pathways. Frontiers in pharmacology. 2016;7:305.

167. Campbell SM, Godman B, Diogene E, Furst J, Gustafsson LL, MacBride-Stewart S, et al. Quality indicators as a tool in improving the introduction of new medicines. Basic \& clinical pharmacology \& toxicology. 2015;116(2):146-57.

168. Godman B, Shrank W, Andersen M, Berg C, Bishop I, Burkhardt T, et al. Policies to enhance prescribing efficiency in europe: findings and future implications. Frontiers in pharmacology. 2010;1:141.

169. Moorkens E, Vulto AG, Huys I, Dylst P, Godman B, Keuerleber S, et al. Policies for biosimilar uptake in Europe: An overview. PloS one. 2017;12(12):e0190147.

170. Bochenek T, Abilova V, Alkan A, Asanin B, de Miguel Beriain I, Besovic Z, et al. Systemic Measures and Legislative and Organizational Frameworks Aimed at Preventing or Mitigating Drug Shortages in 28 European and Western Asian Countries. Frontiers in pharmacology. 2017;8:942. 171. Godman B, Grobler C, Van-De-Lisle M, Wale J, Barbosa WB, Massele A, et al. Pharmacotherapeutic interventions for bipolar disorder type II: addressing multiple symptoms and approaches with a particular emphasis on strategies in lower and middle-income countries. Expert opinion on pharmacotherapy. 2019;20(18):2237-55.

172. World Bank. World Bank Country and Lending Groups - Country Classifictions. 2018. Available at URL: https://datahelpdesk.worldbank.org/knowledgebase/articles/906519-world-bankcountry-and-lending-groups. 
173. Cameron A, Ewen M, Ross-Degnan D, Ball D, Laing R. Medicine prices, availability, and affordability in 36 developing and middle-income countries: a secondary analysis. Lancet. 2009;373(9659):240-9.

174. Ofori-Asenso R, Agyeman AA. Irrational Use of Medicines-A Summary of Key Concepts. Pharmacy 2016;4, 35.

175. Aregbeshola BS, Khan SM. Out-of-Pocket Payments, Catastrophic Health Expenditure and Poverty Among Households in Nigeria 2010. International journal of health policy and management. 2018;7(9):798-806.

176. OECD. Pharmaceutical spending \% of health spending, 2018 or latest available. 2018. Available at URL: https://data.oecd.org/healthres/pharmaceutical-spending.htm.

177. Godman B, Oortwijn W, de Waure C, Mosca I, Puggina A, Specchia ML et al. Links between Pharmaceutical R\&D Models and Access to Affordable Medicines. A Study for the ENVI COMMITTEE. Available at URL:

http://www.europarl.europa.eu/RegData/etudes/STUD/2016/587321/IPOL_STU(2016)587321_EN.p df.

178. Nashilongo MM, Singu B, Kalemeera F, Mubita M, Naikaku E, Baker A, et al. Assessing Adherence to Antihypertensive Therapy in Primary Health Care in Namibia: Findings and Implications. Cardiovascular drugs and therapy. 2017;31(5-6):565-78.

179. Soleymani F, Godman B, Dehghan M, Yarimanesh P, Kebriaeezade A. Prescribing patterns of physicians working in both the direct and indirect treatment sectors in Iran; findings and implications. JPHSR 2019 (EPrint DOI 10.1111/jphs.12322

ISSN 1759-8885)

180. Tiroyakgosi C, Matome M, Summers E, Mashalla Y, Paramadhas BA, Souda S, et al. Ongoing initiatives to improve the use of antibiotics in Botswana: University of Botswana symposium meeting report. Expert review of anti-infective therapy. 2018;16(5):381-4.

181. Kotwani A, Wattal C, Joshi PC, Holloway K. Irrational use of antibiotics and role of the pharmacist: an insight from a qualitative study in New Delhi, India. Journal of clinical pharmacy and therapeutics. 2012;37(3):308-12.

182. Kamati M, Godman B, Dan Kibuule D. PREVALENCE OF SELF-MEDICATION FOR ACUTE RESPIRATORY INFECTIONS IN NAMIBIA; FINDINGS AND IMPLICATIONS. 2019. In Press Journal of Research in Pharmacy Practice.

183. Fink G, D'Acremont $\mathrm{V}$, Leslie $\mathrm{H}$, Cohen J. Antibiotic exposure among children under age five: A crosssectional analysis of nationally representative facility and household surveys in 8 low- and middle-income countries. 2019. In Press Lancet Infectious Diseases.

184. Cotton M, Innes S, Jaspan H, Madide A, Rabie H. Management of upper respiratory tract infections in children. South African family practice. 2008;50(2):6-12.

185. Kumar P, Medigeshi GR, Mishra VS, Islam M, Randev S, Mukherjee A, et al. Etiology of Acute Respiratory Infections in Infants: A Prospective Birth Cohort Study. The Pediatric infectious disease journal. 2017;36(1):25-30.

186. Tregoning JS, Schwarze J. Respiratory viral infections in infants: causes, clinical symptoms, virology, and immunology. Clinical microbiology reviews. 2010;23(1):74-98.

187. He Y, Lin GY, Wang Q, Cai XY, Zhang YH, Lin CX, et al. A 3-year prospective study of the epidemiology of acute respiratory viral infections in hospitalized children in Shenzhen, China. Influenza and other respiratory viruses. 2014;8(4):443-51.

188. Selwyn BJ. The epidemiology of acute respiratory tract infection in young children: comparison of findings from several developing countries. Coordinated Data Group of BOSTID Researchers. Reviews of infectious diseases. 1990;12 Suppl 8:S870-88.

189. Heikkinen T, Jarvinen A. The common cold. Lancet. 2003;361(9351):51-9.

190. Stover CS, Litwin CM. The Epidemiology of Upper Respiratory Infections at a Tertiary Care Center: Prevalence, Seasonality, and Clinical Symptoms. J Respir Med. 2014, Article ID 469393, 1-8. Available at URL: https://www.hindawi.com/journals/jrm/2014/469393/cta/ 
191. Poole MD. Acute bacterial rhinosinusitis: clinical impact of resistance and susceptibility. The American journal of medicine. 2004;117 Suppl 3A:29s-38s.

192. Zoorob R, Sidani MA, Fremont RD, Kihlberg C. Antibiotic use in acute upper respiratory tract infections. American family physician. 2012;86(9):817-22.

193. Klein JO. Is acute otitis media a treatable disease? N Engl J Med. 2011;364(2):168-9.

194. Mayo Clinic. Common cold. Patient Care \& Health Information. 2018. Available at URL: https://www.mayoclinic.org/diseases-conditions/common-cold/symptoms-causes/syc-20351605. 195. Turner RB. Epidemiology, pathogenesis, and treatment of the common cold. Annals of allergy, asthma \& immunology. 1997;78(6):531-9; quiz 9-40.

196. Meneghetti A. Upper Respiratory Tract Infection. Pulmonology, Medscape. 2018. Available at URL: https://emedicine.medscape.com/article/302460-overview\#showall.

197. Petersen I, Johnson AM, Islam A, Duckworth G, Livermore DM, Hayward AC. Protective effect of antibiotics against serious complications of common respiratory tract infections: retrospective cohort study with the UK General Practice Research Database. BMJ. 2007;335(7627):982.

198. Asner SA, Petrich A, Hamid JS, Mertz D, Richardson SE, Smieja M. Clinical severity of rhinovirus/enterovirus compared to other respiratory viruses in children. Influenza and other respiratory viruses. 2014;8(4):436-42.

199. Tan CE, Mohd Roozi AH, Wong WHR, Sabaruddin SAH, Ghani NI, Che Man Z. Intention to Seek Medical Consultation for Symptoms of Upper Respiratory Tract Infection- A Cross-Sectional Survey. Int Med J Malay. 2015; 14 (2): 9-15. Available at URL:

http://iiumedic.net/imjm/v1/download/Volume\%2014\%20No\%202/original_articles/Pages-fromIMJM-Dec-2015-Final-V1-p09-15.pdf.

200. Lee MHM, Pan DST, Huang JH, Chen MI, Chong JWC, Goh EH, et al. Results from a PatientBased Health Education Intervention in Reducing Antibiotic Use for Acute Upper Respiratory Tract Infections in the Private Sector Primary Care Setting in Singapore. Antimicrob Agents Chemother. 2017;61(5).

201. Ng CJ, Chia YC, Teng CL, Nik-Sherina H. Factors influencing parental decision to consult for children with upper respiratory tract infection. Journal of paediatrics and child health. 2008;44(4):208-13.

202. Biezen R, Brijnath B, Grando D, Mazza D. Management of respiratory tract infections in young children-A qualitative study of primary care providers' perspectives. NPJ primary care respiratory medicine. 2017;27(1):15.

203. Abu Hammour K, Abu Farha R, Alsous M, Rizik M, Abu Hammour W. Evaluation of risk factors affecting parental knowledge and attitude toward antibiotic use in children with upper respiratory tract infections. European Journal of Integrative Medicine. 2018;17:107-11.

204. Pan DS, Huang JH, Lee MH, Yu Y, Chen MI, Goh EH, et al. Knowledge, attitudes and practices towards antibiotic use in upper respiratory tract infections among patients seeking primary health care in Singapore. BMC Fam Pract. 2016;17(1):148.

205. Teng $\mathrm{CL}$. Antibiotic prescribing for upper respiratory tract infections in the Asia-Pacific region: A brief review. Malaysian family physician : the official journal of the Academy of Family Physicians of Malaysia. 2014;9(2):18-25.

206. Easton G, Saxena S. Antibiotic prescribing for upper respiratory tract infections in children: how can we improve? London journal of primary care. 2010;3(1):37-41.

207. Renati S, Linder JA. Necessity of office visits for acute respiratory infections in primary care. Fam Pract. 2016;33(3):312-7.

208. McNulty CA, Nichols T, French DP, Joshi P, Butler CC. Expectations for consultations and antibiotics for respiratory tract infection in primary care: the RTI clinical iceberg. The British journal of general practice. 2013;63(612):e429-36.

209. Fletcher-Lartey S, Yee M, Gaarslev C, Khan R. Why do general practitioners prescribe antibiotics for upper respiratory tract infections to meet patient expectations: a mixed methods study. BMJ open. 2016;6(10):e012244. 
210. Braun BL, Fowles JB. Characteristics and experiences of parents and adults who want antibiotics for cold symptoms. Archives of family medicine. 2000;9(7):589-95.

211. Waitumbi JN, Kuypers J, Anyona SB, Koros JN, Polhemus ME, Gerlach J, et al. Outpatient upper respiratory tract viral infections in children with malaria symptoms in Western Kenya. Am J Trop Med Hyg. 2010;83(5):1010-3.

212. Holloway K, Mathai E, Gray A. Surveillance of community antimicrobial use in resourceconstrained settings--experience from five pilot projects. Trop Med Int Health. 2011;16(2):152-61.

213. Hak E, Rovers MM, Kuyvenhoven MM, Schellevis FG, Verheij TJ. Incidence of GP-diagnosed respiratory tract infections according to age, gender and high-risk co-morbidity: the Second Dutch National Survey of General Practice. Fam Pract. 2006;23(3):291-4.

214. Masavkar SP, Naikwadi AM. Study of incidence of upper respiratory tract infections in urban and rural population. Sch J App Med Sci. 2016; 4(6C): 2023-2026. Available at URL: https://pdfs.semanticscholar.org/13c3/d448bfa38ed3edc4de7ac49cb3bb98ca12ff.pdf.

215. Koch A, Sorensen P, Homoe P, Molbak K, Pedersen FK, Mortensen T, et al. Population-based study of acute respiratory infections in children, Greenland. Emerging infectious diseases.

2002;8(6):586-93.

216. Harsten G, Prellner K, Heldrup J, Kalm O, Kornfalt R. Acute respiratory tract infections in children. A three-year follow-up from birth. Acta paediatrica Scandinavica. 1990;79(4):402-9.

217. Rovers MM, Balemans WA, Sanders EA, van der Ent CK, Zielhuis GA, Schilder AG. Persistence of upper respiratory tract infections in a cohort followed from childhood to adulthood. Fam Pract. 2006;23(3):286-90.

218. Kvaerner KJ, Nafstad P, Jaakkola JJ. Upper respiratory morbidity in preschool children: a cross-sectional study. Archives of otolaryngology--head \& neck surgery. 2000;126(10):1201-6.

219. Benediktsdottir B. Upper airway infections in preschool children--frequency and risk factors. Scandinavian journal of primary health care. 1993;11(3):197-201.

220. Leung AK, Newman R, Kumar A, Davies HD. Rapid antigen detection testing in diagnosing group $A$ beta-hemolytic streptococcal pharyngitis. Expert review of molecular diagnostics. 2006;6(5):761-6.

221. Pichichero ME. Group A beta-hemolytic streptococcal infections. Pediatrics in review. 1998;19(9):291-302.

222. Cohen JF, Bertille N, Cohen R, Chalumeau M. Rapid antigen detection test for group A streptococcus in children with pharyngitis. The Cochrane database of systematic reviews. 2016;7:Cd010502.

223. NATIONAL INSTITUTE FOR HEALTH AND CARE EXCELLENCE Guideline. Sore throat (acute): antimicrobial prescribing. 2017. Available at URL: https://www.nice.org.uk/guidance/ng84/documents/draft-guidance.

224. Kim NN, Marikar D. Antibiotic prescribing for upper respiratory tract infections: NICE guidelines. Arch Dis Child Educ Pract Ed. 2019

225. Arroll B. Antibiotics for upper respiratory tract infections: an overview of Cochrane reviews. Respir Med. 2005;99(3):255-61.

226. Wong DM, Blumberg DA, Lowe LG. Guidelines for the use of antibiotics in acute upper respiratory tract infections. American family physician. 2006;74(6):956-66.

227. NICE Guidance. Respiratory tract infections (selflimiting): prescribing antibiotics (CG69). 2008. Available at URL: https://www.nice.org.uk/guidance/cg69/resources/respiratory-tractinfections-selflimiting-prescribing-antibiotics-pdf-975576354757.

228. Kenealy T, Arroll B. Antibiotics for the common cold and acute purulent rhinitis. The Cochrane database of systematic reviews. 2013(6):Cd000247.

229. de Bie S, Kaguelidou F, Verhamme KM, De Ridder M, Picelli G, Straus SM, et al. Using Prescription Patterns in Primary Care to Derive New Quality Indicators for Childhood Community Antibiotic Prescribing. The Pediatric infectious disease journal. 2016;35(12):1317-23. 
230. Butt AA, Navasero CS, Thomas B, Marri SA, Katheeri HA, Thani AA, et al. Antibiotic prescription patterns for upper respiratory tract infections in the outpatient Qatari population in the private sector. International journal of infectious diseases2017;55:20-3.

231. Ahiabu MA, Tersbol BP, Biritwum R, Bygbjerg IC, Magnussen P. A retrospective audit of antibiotic prescriptions in primary health-care facilities in Eastern Region, Ghana. Health Policy Plan. 2016;31(2):250-8.

232. Matome M, Kgatlwane J, Massele A, Godman B. Antibiotic prescribing patterns for URTIs among private practitioners in Botswana; findings and implications. MURIA 4; 2018: 18. Available at URL: file:///C:/Users/mail/Downloads/Consolidated-abstract-booklet\%20(4).pdf.

233. Kotwani A, Holloway K. Antibiotic prescribing practice for acute, uncomplicated respiratory tract infections in primary care settings in New Delhi, India. Trop Med Int Health. 2014;19(7):761-8.

234. Bhanwra S. A study of non-prescription usage of antibiotics in the upper respiratory tract infections in the urban population. Journal of Pharmacology \& Pharmacotherapeutics. 2013;4(1):624.

235. Kunda M, Haoses-Gorases L, Goraseb M. An Investigation of Antibiotic Prescribing in Patients with Upper Respiratory Tract Infections (Urtis) at Katutura Health Centre, Windhoek, Namibia. Single Cell Biol. 2015; 4:122.

236. Kibuule D, Mubita M, Naikaku E, Kalemeera F, Godman BB, Sagwa E. An analysis of policies for cotrimoxazole, amoxicillin and azithromycin use in Namibia's public sector: Findings and therapeutic implications. International journal of clinical practice. 2017;71(2).

237. Sadoh WE, Akinsete AM. Physicians management of sore throat in children in Benin City, Nigeria. Nigerian journal of clinical practice. 2009;12(4):407-11.

238. Ekwochi U, Chinawa JM, Osuorah CD, Odetunde OI, Obu HA, Agwu S. The use of unprescribed antibiotics in management of upper respiratory tract infection in children in Enugu, South East Nigeria. Journal of tropical pediatrics. 2014;60(3):249-52.

239. Ab Rahman N, Teng CL, Sivasampu S. Antibiotic prescribing in public and private practice: a cross-sectional study in primary care clinics in Malaysia. BMC Infect Dis. 2016;16:208.

240. Zimbabwe Antimicrobial Resistance Core Group. Situation Analysis of Antimicrobial Use and Resistance in Humans and Animals in Zimbabwe. 2017. Available at URL:

https://cddep.org/publications/garp-zimbabwe-situation-analysis/

241. Saengcharoen W, Lerkiatbundit S, Kaewmang K. Knowledge, attitudes, and behaviors regarding antibiotic use for upper respiratory tract infections: a survey of Thai students. Southeast Asian J Trop Med Public Health. 2012;43(5):1233-44.

242. Tsiko S. Zimbabwe: AMR Study Reveals Shocking Misuse of Antibiotics in Zim. The Herald 2017. Available at URL: https://allafrica.com/stories/201701170471.html.

243. Lorencatto F, Charani E, Sevdalis N, Tarrant C, Davey P. Driving sustainable change in antimicrobial prescribing practice: how can social and behavioural sciences help? The Journal of antimicrobial chemotherapy. 2018;73(10):2613-24.

244. Birgand G, Castro-Sánchez E, Hansen S, Gastmeier P, Lucet J-C, Ferlie E, et al. Comparison of governance approaches for the control of antimicrobial resistance: Analysis of three European countries. Antimicrobial resistance and infection control. 2018;7:28-.

245. AAFP. 2018-2019 Influenza Vaccine Is Effective, Says CDC. Feb 20 2019. Available at URL: https://www.aafp.org/news/health-of-the-public/20190220fluvaccine.html

246. Costantino C, Vitale F. Influenza vaccination in high-risk groups: a revision of existing guidelines and rationale for an evidence-based preventive strategy. Journal of preventive medicine and hygiene. 2016;57(1):E13-E8.

247. Lundgren F, Maranhao B, Martins R, Chatkin JM, Rabahi MF, Correa RA, et al. Vaccination in the prevention of infectious respiratory diseases in adults. Revista da Associacao Medica Brasileira. 2014;60(1):4-15. 
248. McCullough AR, Parekh S, Rathbone J, Del Mar CB, Hoffmann TC. A systematic review of the public's knowledge and beliefs about antibiotic resistance. The Journal of antimicrobial chemotherapy. 2016;71(1):27-33.

249. Essack SY, Desta AT, Abotsi RE, Agoba EE. Antimicrobial resistance in the WHO African region: current status and roadmap for action. Journal of public health. 2017;39(1):8-13.

250. Meyer JC, Schellack N, Stokes J, Lancaster R, Zeeman H, Defty D, et al. Ongoing Initiatives to Improve the Quality and Efficiency of Medicine Use within the Public Healthcare System in South Africa; A Preliminary Study. Frontiers in pharmacology. 2017;8:751.

251. Wesangula E, Guntai A, Oluka M. KENYAN NATIONAL ACTION PLAN ON ANTIMICROBIALS. 3rd MURIA Training Workshops and Symposium. Available at URL:

file:///C:/Users/mail/Downloads/Kenyan-NAP-Antimicrobials-EWesangula\%252c-AGuantai\%252cMOluka.pdf.

252. Yevutsey SK, Buabeng KO, Aikins M, Anto BP, Biritwum RB, Frimodt-Moller N, et al. Situational analysis of antibiotic use and resistance in Ghana: policy and regulation. BMC public health. 2017;17(1):896.

253. Ronnerstrand B, Lapuente V. Corruption and use of antibiotics in regions of Europe. Health policy. 2017;121(3):250-6.

254. Saleem Z, Hassali MA, Hashmi FK. Pakistan's national action plan for antimicrobial resistance: translating ideas into reality. The Lancet Infectious diseases. 2018;18(10):1066-7.

255. Massele A, Tiroyakgosi C, Matome M, Desta A, Muller A, Paramadhas BD, et al. Research activities to improve the utilization of antibiotics in Africa. Expert review of pharmacoeconomics \& outcomes research. 2017;17(1):1-4.

256. Shongwe K, Wang S-C. Development of Swaziland's National Antimicrobial Resistance Containment Strategic Plan. 2018. Submitted to the US Agency for International Development by the Systems for Improved Access to Pharmaceuticals and Services (SIAPS) Program. Arlington, VA: Management Sciences for Health. Available at URL:

http://siapsprogram.org/publication/altview/development-of-swazilands-national-antimicrobialresistance-containment-strategic-plan/english/.

257. Republic of Kenya. National Policy for the Prevention and Containment of Antimicrobial Resistance, Nairobi, Kenya: Government of Kenya, April 2017. Available at URL:

http://www.health.go.ke/wp-content/uploads/2017/04/Kenya-AMR-Containment-Policy_Final_April.pdf.

258. Ministry of Health Malaysia. National Antibiotic Guidelines. 2014. Available at URL: https://www.pharmacy.gov.my/v2/sites/default/files/document-upload/national-antibioticguideline-2014-full-versionjun2015_1.pdf.

259. Ministry of Health Malaysia. Protocol of Antimicrobial Stewardship (AMS) Program in Healthcare Facilities. 2014. Available at URL:

https://www.bing.com/search?q=Malaysia\%2C+Protocol+of++Antimicrobial+Stewardship+\&form=E DGSPH\&mkt=en-gb\&httpsmsn=1\& refig=213332efe39442b8c24d3012ea336a59\&sp=-

$1 \& p q=$ malaysia\% $2 \mathrm{C}+$ protocol+of+antimicrobial+stewardship $+\& \mathrm{sc}=0$ -

48\&qs=n\&sk=\&cvid=213332efe39442b8c24d3012ea336a59.

260. Sing DYF, Boo YL, Mukhlis R, Chin PW, Hoo FK. Antimicrobial stewardship program in a Malaysian district hospital: First year experience. Pakistan journal of medical sciences. 2016;32(4):999-1004.

261. Bich HNT. Ministry of Health of Vietnam. The National Action Plan on Antimicrobial resistance in Vietnam Period from 2013 to 2020. Available at URL:

file://C:/Users/mail/Desktop/My\%20documents/Ongoing\%20papers/Haque\%20URTIs/Vietnam\%20 AMR\%20PLan.pdf.

262. Chuc NT, Larsson M, Do NT, Diwan VK, Tomson GB, Falkenberg T. Improving private pharmacy practice: a multi-intervention experiment in Hanoi, Vietnam. Journal of clinical epidemiology. 2002;55(11):1148-55. 
263. Vienam Ministry of Health. Project to increase control prescription and selling of prescription drugs period 2017-2020. 2017; Available from: http://emoh.moh.gov.vn/publish/home.

264. Vietnam Mistry of Health. Planning for applying information technology to connect drugs suppliers nationwide to control prescription and selling of prescription drugs. 2018. Available from URL: http://emoh.moh.gov.vn/publish/home.

265. Federal Ministries of Agriculture, Rural Development, Environment and Health, Abuja, Nigeria. National Action Plan for Antimicrobial Resistance, 2017-2022. 2017. Available at URL: https://ncdc.gov.ng/themes/common/docs/protocols/77_1511368219.pdf

266. Matsebula Z, Rosenkranz B, Reuter H. Establishing and monitoring the introduction of an antimicrobial stewardship programme in Swaziland; findings and implications. MURIA 4; 2018: 31. Available at URL: file://C:/Users/mail/Downloads/Consolidated-abstract-booklet\%20(4).pdf.

267. Kalungia AC, Mwambula H, Munkombwe D. Assessment of knowledge and perception on antimicrobial stewardship among physicians and pharmacists at University Teaching Hospitals in Zambia. MURIA 4; 2018: 16-17. Available at URL: file:///C:/Users/mail/Downloads/Consolidatedabstract-booklet\%20(4).pdf.

268. Kalungia AC, Munkombwe M, Marshall M, Lippett S, Jones A St-C. Strengthening antimicrobial stewardship using educational strategies: A proposed conceptual framework for professional capacity building in Zambia. MURIA 4; 2018: 17. Available at URL:

file:///C:/Users/mail/Downloads/Consolidated-abstract-booklet\%20(4).pdf.

269. Kapona O. Zambia Successfully Launches the First Multi-Sectoral National Action Plan on Antimicrobial Resistance (AMR). Health Press Zambia Bull. 2017;1(12): 5-7.

270. Mashalla Y, Setlhare V, Massele A, Sepako E, Tiroyakgosi C, Kgatlwane J, et al. Assessment of prescribing practices at the primary healthcare facilities in Botswana with an emphasis on antibiotics: Findings and implications. International journal of clinical practice. 2017;71(12).

271. Niaz Q, Godman B, Massele A, Campbell S, Kurdi A, Kagoya HR, et al. Validity of World Health Organisation prescribing indicators in Namibia's primary healthcare: findings and implications. Int J Qual Health Care. 2019;31(5):338-345

272. Urbiztondo I, de Oliveira SM, Hernandez-Flores N, Caballero L, Suarez MA, Bjerrum L, et al. General Practitioners' Views on the Acceptability and Applicability of Using Quality Indicators as an Intervention to Reduce Unnecessary Prescription of Antibiotics in Four South American Countries. Antibiotics. 2018;7(3).

273. Kamati M, Godman B, Kibuule D. Prevalence self-medication in acute respiratory infections in the informal settlements in Outapi Region, Namibia. MURIA 4; 2018: 37. Available at URL: file:///C:/Users/mail/Downloads/Consolidated-abstract-booklet\%20(4).pdf.

274. Robertson J, Iwamoto K, Hoxha I, Ghazaryan L, Abilova V, Cvijanovic A, et al. Antimicrobial Medicines Consumption in Eastern Europeand Central Asia - An Updated Cross-National Study and Assessment of QuantitativeMetrics for Policy Action. Frontiers in pharmacology. 2019;9(1156).

275. Santa-Ana-Tellez Y, Mantel-Teeuwisse AK, Leufkens HG, Wirtz VJ. Reply to "decrease in penicillin sales in Brazil after over-the-counter restrictions". Antimicrob Agents Chemother. 2015;59(9):5864.

276. M'ikanatha NM. Antibiotic Stewardship in Ambulatory Care Settings and Surveillance for Enteric Pathogens in Pennsylvania. The Journal of Lancaster General Hospital. 2016; 11 (3): 75-80.

277. Drekonja D, Filice G, Greer N, Olson A, Wilt TJ, MacDonald R et al. Antimicrobial Stewardship Programs in Outpatient Settings: A Systematic Review. VA-ESP Project \#09-009. 2014. Available at URL: https://www.hsrd.research.va.gov/publications/esp/antimicrobial-outpatient.pdf. 278. DART Antibiotics Avoiding Resistance. DART 2020 - Third interim report 2018. Available at URL: https://www.bundesgesundheitsministerium.de/fileadmin/Dateien/3_Downloads/D/DART_2020/B MG_DART2020_3rd-Zwischenbericht_2018_EN.PDF.

279. The Federal Government. DART 2020 - Second Interim Report 2017. Available at URL: https://www.gesundheitsforschung-bmbf.de/files/DART_2020_\%202nd_Interim_Report_2017.pdf. 
280. Molstad S, Lofmark S, Carlin K, Erntell M, Aspevall O, Blad L, et al. Lessons learnt during 20 years of the Swedish strategic programme against antibiotic resistance. Bull World Health Organ. 2017;95(11):764-73.

281. ECDC. Quality indicators for antibiotic consumption in the community in Europe. Available at URL: http://ecdc.europa.eu/en/healthtopics/antimicrobial-resistance-andconsumption/antimicrobial-consumption/esac-net-database/Pages/quality-indicators-primarycare.aspx

282. Nathwani D, Sneddon J, Patton A, Malcolm W. Antimicrobial stewardship in Scotland: impact of a national programme. Antimicrobial Resistance and Infection Control. 2012;1:7-.

283. NHS Lothian. Antimicrobial prescribing guidelines. 2013. Available at URL: https://www.nhslothian.scot.nhs.uk/AntimicrobialPrescribingGuidelines/Pages/default.aspx

284. NHS Fife Antibiotic Guidance for the Treatment of Community Managed Infections. 2014. Available at URL:

file://C:/Users/mail/Desktop/My\%20documents/Ongoing\%20papers/Haque\%20URTIs/primarycare-antibiotic-guidelines-revised\%20NHS\%20Fife.pdf.

285. NHS Highland Formulary. 2018. Available at URL:

file://C:/Users/mail/Desktop/My\%20documents/Ongoing\%20papers/Haque\%20URTIs/highland\%20 formulary\%202018.pdf.

286. Health Protection Scotland. Scottish One Health Antimicrobial Use and Antimicrobial Resistance Report in 2017. Health Protection Scotland, 2018. Available at URL:

https://www.hps.scot.nhs.uk/resourcedocument.aspx?id=6971.

287. Gilchrist M, Wade P, Ashiru-Oredope D, Howard P, Sneddon J, Whitney L, et al. Antimicrobial Stewardship from Policy to Practice: Experiences from UK Antimicrobial Pharmacists. Infect Dis Ther. 2015;4(Suppl 1):51-64.

288. Public Health England. English Surveillance Programme for Antimicrobial Utilisation and Resistance (ESPAUR). 2018 Report. Available at URL:

https://assets.publishing.service.gov.uk/government/uploads/system/uploads/attachment_data/file /759975/ESPAUR_2018_report.pdf.

289. All Wales Medicine Strategy Group. Primary Care Antimicrobial Guidelines. 2015. Available at URL:

http://www.awmsg.org/docs/awmsg/medman/Primary\%20Care\%20Antimicrobial\%20Guidelines.pd f.

290. Nottinghamshire Area Prescribing Committee. Antimicrobial prescribing guidelines for promary care. 2017. Available at URL: http://www.nottsapc.nhs.uk/media/1044/antimicrobialguidelines.pdf.

291. South Central Antimicrobial Network Guidelines for Antibiotic Prescribing in the Community 2018. Available at URL: http://www.nhsantibioticguidelines.org.uk/downloads/CS47131-NHSNHCCGAntibiotic-Guidelines-2018-FINAL-WHOLE-WEB-LIVE-v3.pdf.

292. Ashiru-Oredope D, Hopkins S. Antimicrobial resistance: moving from professional engagement to public action. The Journal of antimicrobial chemotherapy. 2015;70(11):2927-30.

293. HM Government. Tackling antimicrobial resistance 2019-2024 - The UK's five-year national action plan. 2019. Available at URL:

https://assets.publishing.service.gov.uk/government/uploads/system/uploads/attachment_data/file /773130/uk-amr-5-year-national-action-plan.pdf.

294. HOXHA I, MALAJ A, TAKO R, MALAJ L. Survey on how antibiotics are dispensed in community pharmacies in Albania. International Journal of Pharmacy and Pharmaceutical Sciences. 2015;7(7):449-50.

295. Hoxha I, Malaj A, Kraja B, Bino S, Oluka M, Markovic-Pekovic V, et al. Are pharmacists' good knowledge and awareness on antibiotics taken for granted? The situation in Albania and future implications across countries. Journal of global antimicrobial resistance. 2018;13:240-5. 
296. Ministry of Health and Social Security Albania. Barnat pa recetë, intensifikohen kontrollet në farmaci. October 2018. Available at URL: http://www.shendetesia.gov.al/barnat-pa-receteintensifikohen-kontrollet-ne-farmaci/.

297. Ministry of Health and Social Security Albania. Manastirliu ngre "Task Forcë" për kontrollin e barnave. September 2018. Available at URL: http://www.shendetesia.gov.al/manastirliu-ngre-taskforce-per-kontrollin-e-barnave/.

298. Santa-Ana-Tellez Y, Mantel-Teeuwisse AK, Dreser A, Leufkens HG, Wirtz VJ. Impact of overthe-counter restrictions on antibiotic consumption in Brazil and Mexico. PloS one. 2013;8(10):e75550.

299. Santa-Ana-Tellez Y, Mantel-Teeuwisse AK, Leufkens HGM, Wirtz VJ. Seasonal Variation in Penicillin Use in Mexico and Brazil: Analysis of the Impact of Over-the-Counter Restrictions.

Antimicrobial Agents and Chemotherapy. 2015;59(1):105-10.

300. Wirtz VJ, Herrera-Patino JJ, Santa-Ana-Tellez Y, Dreser A, Elseviers M, Vander Stichele RH. Analysing policy interventions to prohibit over-the-counter antibiotic sales in four Latin American countries. Trop Med Int Health. 2013;18(6):665-73.

301. Ghana Ministry of Health, Ministry of Food and Agriculture, Ministry of Environment, Science, Technology and Innovation, Ministry of Fisheries and Aquaculture Development. Ghana National Action Plan for Antimicrobial Use and Resistance. 2017 - 2021. Available at URL: http://www.moh.gov.gh/wp-content/uploads/2018/04/NAP_FINAL_PDF_A4_19.03.2018-SIGNED1.pdf.

302. Fleming Fund - Ghana. Overview of country activity. 2018. Available at URL: https://www.flemingfund.org/countries/ghana/.

303. Versporten A, Bolokhovets G, Ghazaryan L, Abilova V, Pyshnik G, Spasojevic T, et al. Antibiotic use in eastern Europe: a cross-national database study in coordination with the WHO Regional Office for Europe. The Lancet Infectious diseases. 2014;14(5):381-7.

304. Jakupi A, Godman B, Martin A, Haycox A, Baholli I. Utilization and Expenditure of Anti-cancer Medicines in Kosovo: Findings and Implications. PharmacoEconomics - open. 2018;2(4):423-32.

305. Markovic-Pekovic V, Grubisa N. Self-medication with antibiotics in the Republic of Srpska community pharmacies: pharmacy staff behavior. Pharmacoepidemiol Drug Saf. 2012;21(10):1130-3. 306. Markovic-Pekovic V, Grubisa N, Burger J, Bojanic L, Godman B. Initiatives to Reduce Nonprescription Sales and Dispensing of Antibiotics: Findings and Implications. J Res Pharm Pract. 2017;6(2):120-5.

307. Meyer J, Sibanda M. Appropriate use of antimicrobials: An ongoing and coordinated effort. S Afr Pharm J 2016;83(9):41-7.

308. Mendelson M MM. THE SOUTH AFRICAN ANTIMICROBIAL RESISTANCE STRATEGY FRAMEWORK. AMR CONTROL 2015:54-61.

309. SAASP. Mission Statement of the South African Antibiotic Stewardship Programme. 2017. Available at URL: http://www.fidssa.co.za/SAASP

310. Brink AJ, Messina AP, Feldman C, Richards GA, Becker PJ, Goff DA, et al. Antimicrobial stewardship across 47 South African hospitals: an implementation study. The Lancet Infectious diseases. 2016;16(9):1017-25.

311. Schellack N, Bronkhorst E, Coetzee R, Godman B, Gous AGS, Kolman S et al. SASOCP position statement on the pharmacist's role in antibiotic stewardship 2018. South African Journal of Infectious Disease 2018;33(1):28-35.

312. Ncube NBQ, Solanki GC, Kredo T, Lalloo R. Antibiotic prescription patterns of South African general medical practitioners for treatment. MURIA 4; 2018: 19. Available at URL: file:///C:/Users/mail/Downloads/Consolidated-abstract-booklet\%20(4).pdf.

313. Matsitse TB, Helberg E, Meyer JC, Godman B, Massele A, Schellack N. Compliance with the primary health care treatment guidelines and the essential medicines list in the management of sexually transmitted infections in correctional centres in South Africa: findings and implications. Expert review of anti-infective therapy. 2017;15(10):963-72. 
314. Burger M FJ, Lootsa D, Mnisia T, Schellack N, Bezuidenhout S, Meyer JC. Knowledge and perceptions of antimicrobial stewardship concepts among final year pharmacy students in pharmacy schools across South Africa. Southern African Journal of Infectious Diseases . 2016;1(1):1-7.

315. Wasserman S, Potgieter S, Shoul E, Constant D, Stewart A, Mendelson M, et al. South African medical students' perceptions and knowledge about antibiotic resistance and appropriate prescribing: Are we providing adequate training to future prescribers? South African medical journal. 2017;107(5):405-10.

316. TURKISH MEDICINES AND MEDICAL DEVICES AGENCY. PHARMACEUTICAL TRACK AND TRACE SYSTEM (ITS). 2019. Available at URL:

https://www.gs1.org/sites/default/files/docs/healthcare/2019.Noordwijk/PresentationsDay3/02.Day3Turkish-pharmaceutical-track-trace-system-ITS.pdf.

317. Meeker D, Linder JA, Fox CR, Friedberg MW, Persell SD, Goldstein NJ, et al. Effect of Behavioral Interventions on Inappropriate Antibiotic Prescribing Among Primary Care Practices: A Randomized Clinical Trial. Jama. 2016;315(6):562-70.

318. van der Velden A, Duerden MG, Bell J, Oxford JS, Altiner A, Kozlov R, et al. Prescriber and Patient Responsibilities in Treatment of Acute Respiratory Tract Infections - Essential for Conservation of Antibiotics. Antibiotics. 2013;2(2):316-27.

319. Abera B, Kibret M, Mulu W. Knowledge and beliefs on antimicrobial resistance among physicians and nurses in hospitals in Amhara Region, Ethiopia. BMC Pharmacology and Toxicology. 2014;15(1):26.

320. Labi AK, Obeng-Nkrumah N, Bjerrum S, Aryee NAA, Ofori-Adjei YA, Yawson AE, et al. Physicians' knowledge, attitudes, and perceptions concerning antibiotic resistance: a survey in a Ghanaian tertiary care hospital. BMC health services research. 2018;18(1):126.

321. Mosaddek AS, Islam Z, Rahman F, Akter S, Laizu J, Parvin R et al. A Pilot Study on Evaluation of Self-Medication among Undergraduate Medical Students in Dhaka, Bangladesh. Research J. Pharm. and Tech. 2014; 7(11): 1240-5.

322. Mosaddek AS, Haque M, Islam Z, Sharmin ZR, Sharmin R, Rahman MF et al. Practice of SelfMedication among Students of a Selected Medical College of Dhaka City, Bangladesh. International Medical Journal 2017; 24 (2): 225 - 9

323. Haque M, Rahman NI, Zulkifli Z, Ismail S. Antibiotic prescribing and resistance: knowledge level of medical students of clinical years of University Sultan Zainal Abidin, Malaysia. Therapeutics and clinical risk management. 2016;12:413-26.

324. Hoque R, Mostafa A, Haque M. Intern doctors' views on the current and future antibiotic resistance situation of Chattagram Maa O Shishu Hospital Medical College, Bangladesh. Therapeutics and clinical risk management. 2015;11:1177-85.

325. Hoque R, Mostafa A, Haque M. Insight of Medical Students of Clinical Years to Antimicrobials Prescribing and Resistance in Private Medical School, Chittagong, Bangladesh. J Young Pharm. 2016; 8(4): 447-455.

326. Haque M, Rahman NAA, McKimm J, Binti Abdullah SL, Islam MZ, Zulkifli Z, et al. A crosssectional study evaluating the knowledge and beliefs about, and the use of antibiotics amongst Malaysian university students. Expert review of anti-infective therapy. 2019:1-10.

327. Saleem Z, Hassali MA, Godman B, Hashmi FK, Saleem F. Antimicrobial prescribing and determinants of antimicrobial resistance: a qualitative study among physicians in Pakistan. International journal of clinical pharmacy. 2019;41(5):1348-58.

328. Lam TP, Lam KF. What are the non-biomedical reasons which make family doctors overprescribe antibiotics for upper respiratory tract infection in a mixed private/public Asian setting? Journal of clinical pharmacy and therapeutics. 2003;28(3):197-201.

329. Moro ML, Marchi M, Gagliotti C, Di Mario S, Resi D. Why do paediatricians prescribe antibiotics? Results of an Italian regional project. BMC pediatrics. 2009;9:69. 
330. Riaz H, Godman B, Hussain S, Malik F, Mahmood S, Shami A, Bashir S. Prescribing of bisphosphonates and antibiotics in Pakistan: challenges and opportunities for the future. JPHSR 2015;6:111-21.

331. Fadare JO, Oshikoya KA, Ogunleye OO, Desalu OO, Ferrario A, Enwere OO, et al. Drug promotional activities in Nigeria: impact on the prescribing patterns and practices of medical practitioners and the implications. Hospital practice. 2018;46(2):77-87.

332. Holmes EAF, Harris SD, Hughes A, Craine N, Hughes DA. Cost-Effectiveness Analysis of the Use of Point-of-Care C-Reactive Protein Testing to Reduce Antibiotic Prescribing in Primary Care. Antibiotics. 2018;7(4).

333. Gonzales R, Anderer T, McCulloch CE, Maselli JH, Bloom FJ, Jr., Graf TR, et al. A cluster randomized trial of decision support strategies for reducing antibiotic use in acute bronchitis. JAMA Intern Med. 2013;173(4):267-73.

334. Hallsworth M, Chadborn T, Sallis A, Sanders M, Berry D, Greaves F, et al. Provision of social norm feedback to high prescribers of antibiotics in general practice: a pragmatic national randomised controlled trial. Lancet. 2016;387(10029):1743-52.

335. Fernandez Urrusuno R, Flores Dorado M, Vilches Arenas A, Serrano Martino C, Corral Baena $\mathrm{S}$, Montero Balosa MC. Improving the appropriateness of antimicrobial use in primary care after implementation of a local antimicrobial guide in both levels of care. European journal of clinical pharmacology. 2014;70(8):1011-20.

336. Sun Q, Dyar OJ, Zhao L, Tomson G, Nilsson LE, Grape M, et al. Overuse of antibiotics for the common cold - attitudes and behaviors among doctors in rural areas of Shandong Province, China. BMC Pharmacol Toxicol. 2015;16:6.

337. Esmaily HM, Silver I, Shiva S, Gargani A, Maleki-Dizaji N, Al-Maniri A, et al. Can rational prescribing be improved by an outcome-based educational approach? A randomized trial completed in Iran. The Journal of continuing education in the health professions. 2010;30(1):11-8.

338. Rambaud-Althaus C, Shao A, Samaka J, Swai N, Perri S, Kahama-Maro J, et al. Performance of Health Workers Using an Electronic Algorithm for the Management of Childhood Illness in Tanzania: A Pilot Implementation Study. Am J Trop Med Hyg. 2017;96(1):249-57.

339. Tuon FF, Gasparetto J, Wollmann LC, Moraes TPd. Mobile health application to assist doctors in antibiotic prescription - an approach for antibiotic stewardship. The Brazilian Journal of Infectious Diseases. 2017;21(6):660-4.

340. Yoon CH, Ritchie SR, Duffy EJ, Thomas MG, McBride S, Read K, et al. Impact of a smartphone app on prescriber adherence to antibiotic guidelines in adult patients with community acquired pneumonia or urinary tract infections. PloS one. 2019;14(1):e0211157.

341. Yip W, Powell-Jackson T, Chen W, Hu M, Fe E, Hu M, et al. Capitation combined with pay-forperformance improves antibiotic prescribing practices in rural China. Health affairs. 2014;33(3):50210.

342. Shrestha N, Samir KC, Baltussen R, Kafle KK, Bishai D, Niessen L. Practical approach to lung health in Nepal: better prescribing and reduction of cost. Trop Med Int Health. 2006;11(5):765-72.

343. Kafle KK, Bhuju GB, Karkee SB, Prasad RR, Shrestha N, Shrestha AD, et al. An intervention improving prescribing practices and monitoring drugs availability in a district. Nepal Medical College journal : NMCJ. 2009;11(4):217-21.

344. Awad Al, Eltayeb IB, Baraka OZ. Changing antibiotics prescribing practices in health centers of Khartoum State, Sudan. European journal of clinical pharmacology. 2006;62(2):135-42.

345. Adriaenssens N, Coenen S, Tonkin-Crine S, Verheij TJ, Little P, Goossens H. European Surveillance of Antimicrobial Consumption (ESAC): disease-specific quality indicators for outpatient antibiotic prescribing. BMJ quality \& safety. 2011;20(9):764-72.

346. Coenen S, Ferech M, Haaijer-Ruskamp FM, Butler CC, Vander Stichele RH, Verheij TJ, et al. European Surveillance of Antimicrobial Consumption (ESAC): quality indicators for outpatient antibiotic use in Europe. Quality \& safety in health care. 2007;16(6):440-5. 
347. WHO. Antimicrobial Medicines Consumption (AMC) Network. 2017. Available at URL: http://www.euro.who.int/en/publications/abstracts/antimicrobial-medicines-consumption-amcnetwork.-amc-data-20112014-2017

348. Nakwatumbah S, Kibuule D, Godman B, Haakuria V, Kalemeera F, Baker A, et al. Compliance to guidelines for the prescribing of antibiotics in acute infections at Namibia's national referral hospital: a pilot study and the implications. Expert review of anti-infective therapy. 2017;15(7):71321.

349. Mashalla YJ, Sepako E, Setlhare V, Chuma M, Bulang M, Massele AY. Availability of guidelines and policy documents for enhancing performance of practitioners at the Primary Health Care (PHC) facilities in Gaborone, Tlokweng and Mogoditshane, Republic of Botswana. J Public Health Epidemiol. 2016;8(8):127-35.

350. Roberts RM, Hicks LA, Bartoces M. Variation in US outpatient antibiotic prescribing quality measures according to health plan and geography. The American journal of managed care. 2016;22(8):519-23.

351. Le Maréchal M, Tebano G, Monnier AA, Adriaenssens N, Gyssens IC, Huttner B, et al. Quality indicators assessing antibiotic use in the outpatient setting: a systematic review followed by an international multidisciplinary consensus procedure. The Journal of antimicrobial chemotherapy. 2018;73(suppl_6):vi40-vi9.

352. Lind J, Schafheutle E, Hagg AN, Sporrong SK. General sale of non-prescription medicinal products: Comparing legislation in two European countries. Research in social \& administrative pharmacy. 2016;12(1):68-77.

353. Chipwaza B, Mugasa JP, Mayumana I, Amuri M, Makungu C, Gwakisa PS. Self-medication with anti-malarials is a common practice in rural communities of Kilosa district in Tanzania despite the reported decline of malaria. Malaria Journal. 2014;13(1):252.

354. Hadi MA, Karami NA, Al-Muwalid AS, Al-Otabi A, Al-Subahi E, Bamomen A, et al. Community pharmacists' knowledge, attitude, and practices towards dispensing antibiotics without prescription (DAwP): a cross-sectional survey in Makkah Province, Saudi Arabia. International journal of infectious diseases 2016;47:95-100.

355. Ramay BM, Lambour P, Cerón A. Comparing antibiotic self-medication in two socioeconomic groups in Guatemala City: a descriptive cross-sectional study. BMC Pharmacology \& Toxicology. 2015;16:11.

356. Hussain A , Ibrahim MIM , Malik M. Assessment of disease management of acute respiratory tract infection at community pharmacies through simulated visits in Pakistan. Lat Am J Pharm 2012;31:1435-40.

357. Fleming N, Barbar S, Ashiru-Oredope D. Pharmacists have a critical role in the conservation of effective antibiotics. Pharmaceutical Journal. 2011;287(7675):465.

358. Mukokinya M, Opanga S, Oluka M, Godman B. Dispensing of antimicrobials in Kenya: A cross-sectional pilot study and its implications. Journal of Research in Pharmacy Practice.

2018;7(2):77-82.

359. Mbui JM, Oluka MN, Guantai EM, Sinei KA, Achieng L, Baker A, et al. Prescription patterns and adequacy of blood pressure control among adult hypertensive patients in Kenya; findings and implications. Expert review of clinical pharmacology. 2017;10(11):1263-71.

360. FIP. FIP statement of policy - control of antimicrobial medicines resistance (AMR). Available from URL: http://www.fip.org/www/uploads/database_file.php?id=289\&table_id

361. WHO. The role of pharmacist in encouraging prudent use of antibiotics and averting antimicrobial resistance: a review of policy and experience. Available at URL:

http://www.euro.who.int/_data/assets/pdf_file/0006/262815/The-role-of-pharmacist-inencouraging-prudent-use-of-antibiotics-and-averting-antimicrobial-resistance-a-review-of-policyand-experience-Eng.pdf?ua=1 
362. Ahmad A, Khan MU, Moorthy J, Jamshed SQ, Patel I. Comparison of knowledge and attitudes about antibiotics and resistance, and antibiotics self-practicing between Bachelor of Pharmacy and Doctor of Pharmacy students in Southern India. Pharmacy practice. 2015;13(1):523.

363. Chang J, Ye D, Lv B, Jiang M, Zhu S, Yan K, et al. Sale of antibiotics without a prescription at community pharmacies in urban China: a multicentre cross-sectional survey. The Journal of antimicrobial chemotherapy. 2017;72(4):1235-42.

364. Eslami N, Eshraghi A, Vaseghi G, Mehdizadeh M, Masjedi M, Mehrpooya M. Pharmacists' Knowledge and Attitudes Towards Upper Respiratory Infections (URI) in Iran: A Cross Sectional Study. Rev Recent Clin Trials. 2016;11(4):342-5.

365. Zapata-Cachafeiro M, González-González C, Váquez-Lago JM, López-Vázquez P, López-Durán $A$, Smyth $E$, et al. Determinants of antibiotic dispensing without a medical prescription: a crosssectional study in the north of Spain. Journal of Antimicrobial Chemotherapy. 2014;69(11):3156-60. 366. Donkor ES, Tetteh-Quarcoo PB, Nartey P, Agyeman IO. Self-medication practices with antibiotics among tertiary level students in Accra, Ghana: a cross-sectional study. Int J Environ Res Public Health. 2012;9.

367. Zawahir S, Lekamwasam S, Aslani P. A cross-sectional national survey of community pharmacy staff: Knowledge and antibiotic provision. PloS one. 2019;14(4):e0215484-e.

368. Saleem Z, Hassali MA, Hashmi FK, et al. Antimicrobial dispensing practices and determinants of antimicrobial resistance: a qualitative study among community pharmacists in Pakistan. Fam Med Com Health 2019;7:e000138.

369. Almaaytah A, Mukattash TL, Hajaj J. Dispensing of non-prescribed antibiotics in Jordan. Patient preference and adherence. 2015;9:1389-95.

370. Charani E, Smith I, Skodvin B, Perozziello A, Lucet JC, Lescure FX, et al. Investigating the cultural and contextual determinants of antimicrobial stewardship programmes across low-, middleand high-income countries-A qualitative study. PloS one. 2019;14(1):e0209847.

371. Al-Mohamadi A, Badr A, Bin Mahfouz L, Samargandi D, Al Ahdal A. Dispensing medications without prescription at Saudi community pharmacy: Extent and perception. Saudi Pharmaceutical Journal. 2013;21(1):13-8.

372. Moura ML, Boszczowski I, Mortari N, Barrozo LV, Chiaravalloti Neto F, Lobo RD, et al. The Impact of Restricting Over-the-Counter Sales of Antimicrobial Drugs: Preliminary Analysis of National Data. Medicine. 2015;94(38):e1605.

373. Lopes-Junior R, de Sa Del Fiol F, Araujo JL, de Toledo MI, Barberato-Filho S. Decrease in penicillin Sales in Brazil after over-the-counter restrictions. Antimicrob Agents Chemother. 2015;59(9):5862-3.

374. Roque F, Soares S, Breitenfeld L, López-Durán A, Figueiras A, Herdeiro MT. Attitudes of community pharmacists to antibiotic dispensing and microbial resistance: a qualitative study in Portugal. International journal of clinical pharmacy. 2013;35(3):417-24.

375. Lim KK, Teh CC. A Cross Sectional Study of Public Knowledge and Attitude towards Antibiotics in Putrajaya, Malaysia. Southern med review. 2012;5(2):26-33.

376. Monnet DL, Safrany N, Heine N, Price C. Comment on: A systematic review of the public's knowledge and beliefs about antibiotic resistance. The Journal of antimicrobial chemotherapy. 2016;71(8):2364-5.

377. Elong Ekambi G-A, Okalla Ebongue C, Penda IC, Nnanga Nga E, Mpondo Mpondo E, Eboumbou Moukoko CE. Knowledge, practices and attitudes on antibiotics use in Cameroon: Selfmedication and prescription survey among children, adolescents and adults in private pharmacies. PloS one. 2019;14(2):e0212875.

378. Behaviour change for antibiotic prescribing in healthcare settings. Literarure review and behavioural analysis. 2015. Available at URL:

https://assets.publishing.service.gov.uk/government/uploads/system/uploads/attachment_data/file /405031/Behaviour_Change_for_Antibiotic_Prescribing_-_FINAL.pdf. 
379. Ivanovska V, Angelovska B, van Dijk L, Zdravkovska M, Leufkens HG, Mantel-Teeuwisse AK. Change in parental knowledge, attitudes and practice of antibiotic use after a national intervention programme. European journal of public health. 2018;28(4):724-9.

380. Cabral C, Ingram J, Lucas PJ, Redmond NM, Kai J, Hay AD, et al. Influence of Clinical Communication on Parents' Antibiotic Expectations for Children With Respiratory Tract Infections. Ann Fam Med. 2016;14(2):141-7.

381. Coenen S, Francis N, Kelly M, Hood K, Nuttall J, Little P, et al. Are patient views about antibiotics related to clinician perceptions, management and outcome? A multi-country study in outpatients with acute cough. PloS one. 2013;8(10):e76691.

382. Doctors and local media: a synergy for public health information?: a controlled trial to evaluate the effects of a multifaceted campaign on antibiotic prescribing (protocol). BMC public health. 2011;11:816.

383. Hornik R, Kelly B. Communication and diet: an overview of experience and principles. Journal of nutrition education and behavior. 2007;39(2 Suppl):S5-12.

384. Bjorkhem-Bergman L, Andersen-Karlsson E, Laing R, Diogene E, Melien O, Jirlow M, et al. Interface management of pharmacotherapy. Joint hospital and primary care drug recommendations. European journal of clinical pharmacology. 2013;69 Suppl 1:73-8.

385. Gustafsson LL, Wettermark B, Godman B, Andersen-Karlsson E, Bergman U, Hasselstrom J, et al. The 'wise list'- a comprehensive concept to select, communicate and achieve adherence to recommendations of essential drugs in ambulatory care in Stockholm. Basic \& clinical pharmacology \& toxicology. 2011;108(4):224-33.

386. Eriksen J, Gustafsson LL, Ateva K, Bastholm-Rahmner P, Ovesjo ML, Jirlow M, et al. High adherence to the 'Wise List' treatment recommendations in Stockholm: a 15-year retrospective review of a multifaceted approach promoting rational use of medicines. BMJ open.

2017;7(4):e014345.

387. Sharland M, Pulcini C, Harbarth S, Zeng M, Gandra S, Mathur S, et al. Classifying antibiotics in the WHO Essential Medicines List for optimal use-be AWaRe. The Lancet Infectious diseases. 2018;18(1):18-20.

388. Hsia Y, Sharland M, Jackson C, Wong ICK, Magrini N, Bielicki JA. Consumption of oral antibiotic formulations for young children according to the WHO Access, Watch, Reserve (AWaRe) antibiotic groups: an analysis of sales data from 70 middle-income and high-income countries. The Lancet Infectious diseases. 2019;19(1):67-75. 